\title{
WASTE_ACC: A Computer Model for Analysis of Waste Management Accidents
}

by B.K. Nabelssi, S. Folga, ${ }^{\star}$ E.J. Kohout, ${ }^{\star}$ C.J. Mueller, and J. Roglans-Ribas*

Environmental Assessment Division,

Argonne National Laboratory, 9700 South Cass Avenue, Argonne, Illinois 60439

December 1996

Work sponsored by U.S. Department of Energy,

Assistant Secretary for Environmental Management

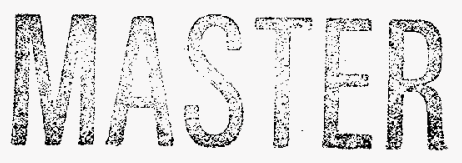

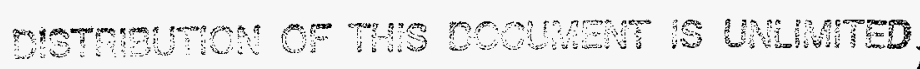

* Folga and Kohout are affiliated with Argonne's Decision and Information Sciences Division. Roglans-Ribas is affiliated with Argonne's Reactor Analysis Division. 


\section{DISCLAIMER}

This report was prepared as an account of work sponsored by an agency of the United States Government. Neither the United States Government nor any agency thereof, nor any of their employees, makes any warranty, express or implied, or assumes any legal liability or responsibility for the accuracy, completeness, or usefulness of any information, apparatus, product, or process disclosed, or represents that its use would not infringe privately owned rights. Reference herein to any specific commercial product, process, or service by trade name, trademark, manufacturer, or otherwise does not necessarily constitute or imply its endorsement, recommendation, or favoring by the United States Government or any agency thereof. The views and opinions of authors expressed herein do not necessarily state or reflect those of the United States Government or any agency thereof. 


\section{DISCLAMVIER}

Portions of this document may be illegible in electronic image products. Images are produced from the best available original document. 
LIST OF ACRONYMS $\ldots \ldots \ldots \ldots \ldots \ldots \ldots \ldots \ldots \ldots \ldots \ldots \ldots \ldots \ldots \ldots \ldots \ldots \ldots$ vi

ACKNOWLEDGMENTS $\ldots \ldots \ldots \ldots \ldots \ldots \ldots \ldots \ldots \ldots \ldots \ldots \ldots \ldots \ldots$ vii

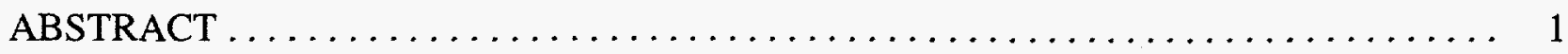

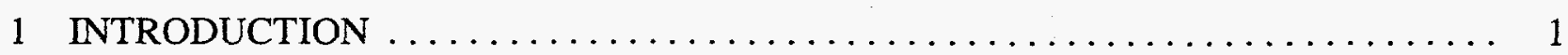

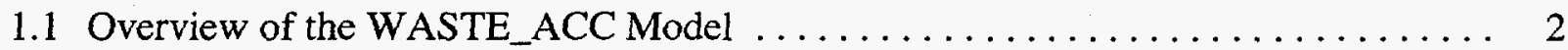

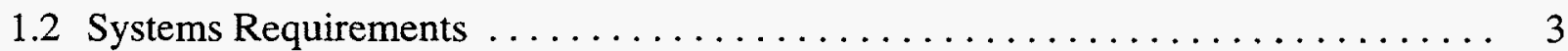

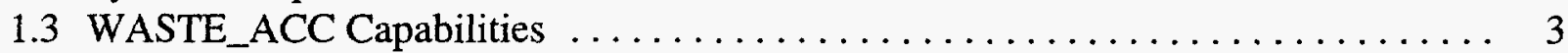

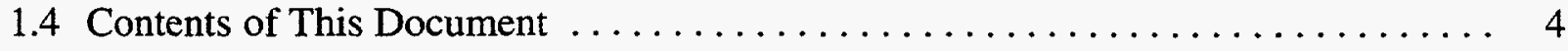

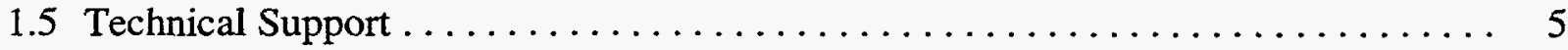

2 ACCIDENT ANALYSIS METHODOLOGY $\ldots \ldots \ldots \ldots \ldots \ldots \ldots \ldots \ldots \ldots$

2.1 Overview of Waste Management Alternatives $\ldots \ldots \ldots \ldots \ldots \ldots \ldots \ldots \ldots$

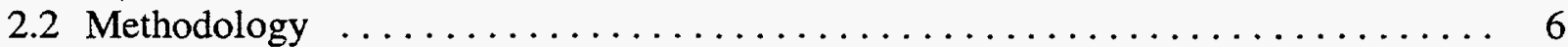

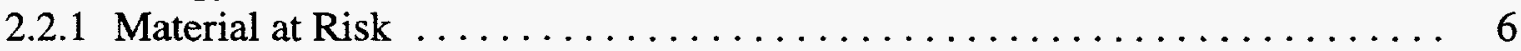

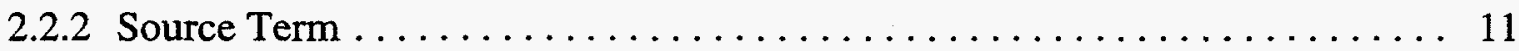

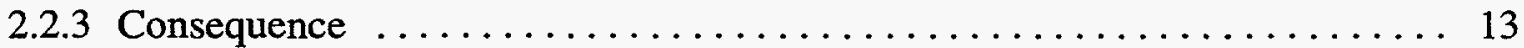

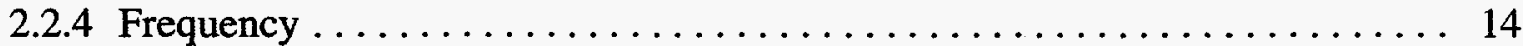

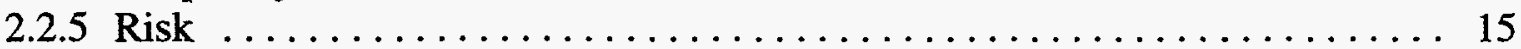

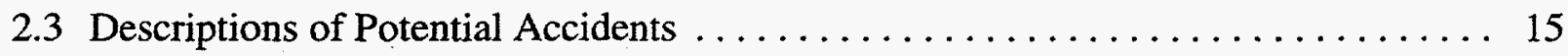

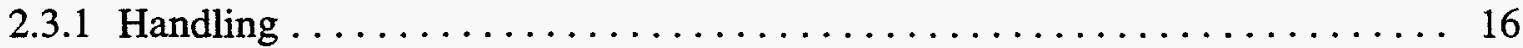

2.3.2 Storage Facility $\ldots \ldots \ldots \ldots \ldots \ldots \ldots \ldots \ldots \ldots \ldots \ldots \ldots \ldots \ldots \ldots \ldots, 18$

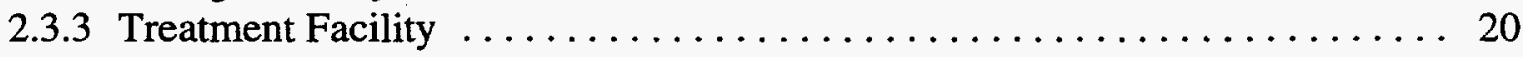

3 DEVELOPMENT AND USE OF THE WASTE_ACC SYSTEM $\ldots \ldots \ldots \ldots \ldots \ldots 24$

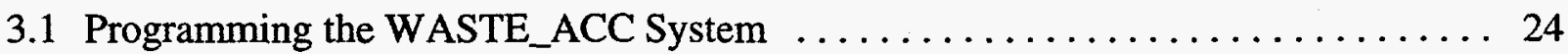

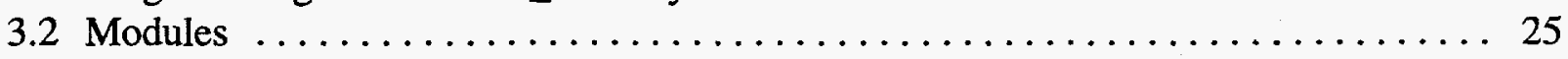

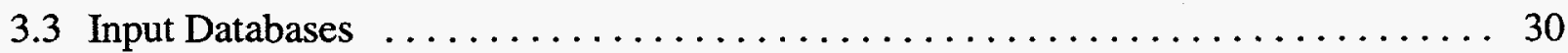

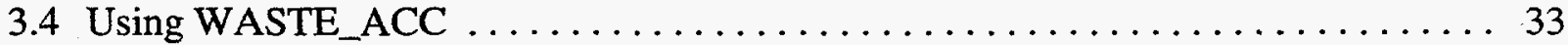

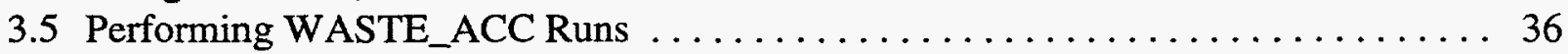

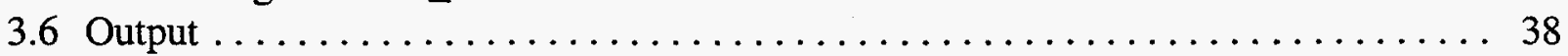

4 SAMPLE ACCIDENT ANALYSIS CALCULATION $\ldots \ldots \ldots \ldots \ldots \ldots \ldots \ldots$

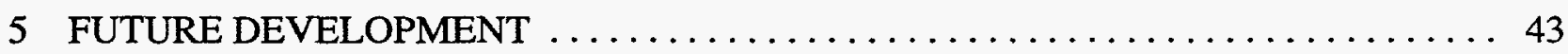

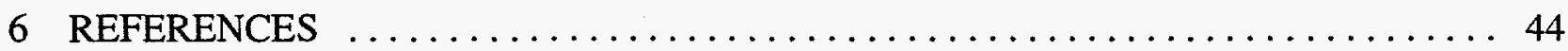




\section{CONTENTS (Cont.)}

APPENDIX A: Radioactive Waste Treatability Categories $\ldots \ldots \ldots \ldots \ldots \ldots \ldots$ A-1

APPENDIX B: WASTE_MGMT: A Computer Model for Calculation of Waste Loads, Waste Profiles, and Emissions ............. B-1

APPENDIX C: WASTE_ETA: A Computer Model for Event Tree Analysis

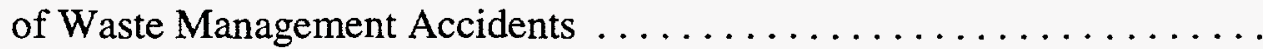

\section{FIGURES}

1 Major Components and Related Input and Output of Data for Facility Accident Analysis

2 Conceptual Flow Diagram for Source Term Development $\ldots \ldots \ldots \ldots \ldots \ldots \ldots .12$

3 Application Process Flow of WASTE_ACC $\ldots \ldots \ldots \ldots \ldots \ldots \ldots \ldots \ldots . \ldots \ldots$

4 Model Implementation Flow of WASTE_ACC $\ldots \ldots \ldots \ldots \ldots \ldots \ldots \ldots . . \ldots \ldots$

5 Bachman Diagram Relating to WASTE_ACC Databases $\ldots \ldots \ldots \ldots \ldots \ldots \ldots . . \ldots$

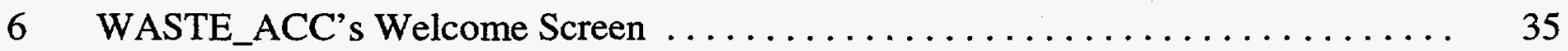

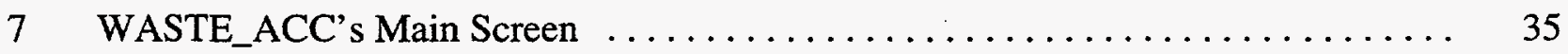

8 An Example of a WASTE_ACC Summary Report Screen $\ldots \ldots \ldots \ldots \ldots \ldots .36$

$9 \quad$ Alternative Selection for Batch Runs $\ldots \ldots \ldots \ldots \ldots \ldots \ldots \ldots \ldots \ldots \ldots \ldots \ldots \ldots$

C.1 Sample Event Tree Input File in WASTE_ETA $\ldots \ldots \ldots \ldots \ldots \ldots \ldots \ldots \ldots \ldots \ldots$ C-8

C.2 Sample of a Master File Used in WASTE_ETA $\ldots \ldots \ldots \ldots \ldots \ldots \ldots \ldots \ldots$ C-10

C.3 Sample WASTE_ETA Output File: File Ready for Database
Loading in WASTE_ACC $\ldots \ldots \ldots \ldots \ldots \ldots \ldots \ldots \ldots \ldots \ldots \ldots \ldots \ldots \ldots \ldots \ldots \ldots$

C.4 Sample WASTE_ETA Output File: Summary of Results $\ldots \ldots \ldots \ldots \ldots \ldots$ C-15

C.5 WASTE_ETA Event Tree Sample Plot $\ldots \ldots \ldots \ldots \ldots \ldots \ldots \ldots \ldots \ldots \ldots \ldots \ldots$ 


\section{TABLES}

1 Dimensions, Weights, and Radioactivities of HLW Canisters

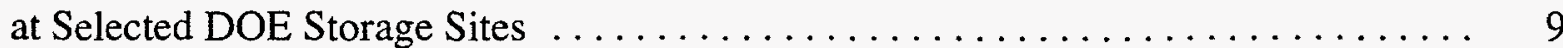

2 Single-Drum Accidents Included in WASTE_ACC $\ldots \ldots \ldots \ldots \ldots \ldots \ldots \ldots$

3 HLW Handling Accidents Included in WASTE_ACC $\ldots \ldots \ldots \ldots \ldots \ldots \ldots$

4 Storage Facility Accidents Included in WASTE_ACC $\ldots \ldots \ldots \ldots \ldots \ldots \ldots . . . . . . .6$

5 Incineration Facility Accidents Included in WASTE_ACC $\ldots \ldots \ldots \ldots \ldots \ldots .21$

6 Organic Destruction Facility Accidents Included in WASTE_ACC $\ldots \ldots \ldots \ldots .23$

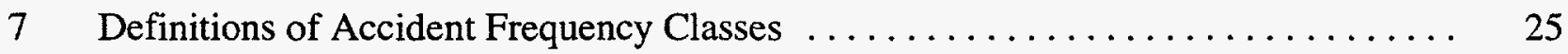

8 Storage Facility Capacity as a Function of Projected Site Inventory .......... 30

9 Sample Calculation for Risk-Dominant Accidents .................. 41

10 Sample Calculation of Source Terms for Risk-Dominant Accidents . . . . . . . . . 42

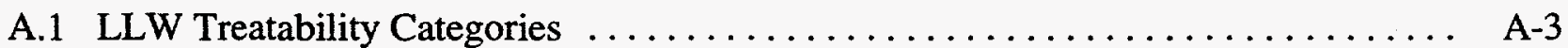

A.2 LLMW Treatability Categories $\ldots \ldots \ldots \ldots \ldots \ldots \ldots \ldots \ldots \ldots \ldots \ldots \ldots \ldots \ldots \ldots \ldots \ldots \ldots$

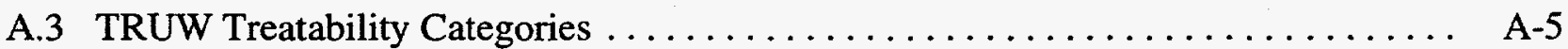




\section{LIST OF ACRONYMS}

The following acronyms appear in this document.

$\begin{array}{ll}\text { ANL } & \text { Argonne National Laboratory } \\ \text { CH } & \text { contact handled } \\ \text { DCF } & \text { release-to-dose conversion factor } \\ \text { DF } & \text { damage fraction } \\ \text { DOE } & \text { U.S. Department of Energy } \\ \text { EBR-II-PRA } & \text { Experimental Breeder Reactor II Probabilistic Risk Assessment } \\ \text { EPA } & \text { U.S. Environmental Protection Agency } \\ \text { ER } & \text { Environmental Restoration } \\ \text { HEPA } & \text { high-efficiency particulate air (filter) } \\ \text { HLW } & \text { high-level waste } \\ \text { HW } & \text { hazardous waste } \\ \text { ICRP } & \text { International Commission on Radiological Protection } \\ \text { LLMW } & \text { low-level mixed waste } \\ \text { LLW } & \text { low-level waste } \\ \text { LPF } & \text { leak path factor } \\ \text { MAR } & \text { material at risk } \\ \text { MEI } & \text { maximally exposed individual } \\ \text { NRC } & \text { U.S. Nuclear Regulatory Commission } \\ \text { ORD } & \text { organic destruction } \\ \text { ORNL } & \text { Oak Ridge National Laboratory } \\ \text { PCB } & \text { polychlorinated biphenyl } \\ \text { PEIS } & \text { Programmatic Environmental Impact Statement } \\ \text { PRA } & \text { Probabilistic Risk Assessment } \\ \text { RARF } & \text { respirable airborne release fraction } \\ \text { RH } & \text { remote handled } \\ \text { TRF } & \text { total release fraction } \\ \text { TRUW } & \text { transuranic waste } \\ \text { TSD } & \text { Treatment, Storage, and Disposal } \\ \text { WIPP } & \text { Waste Isolation Pilot Plant } \\ \text { WM } & \text { Office of Waste Management (U.S. Department of Energy) } \\ & \end{array}$




\section{ACKNOWLEDGMENTS}

The authors thank Melanie Tompkins for her help incorporating the LLMW analysis into the WASTE_ACC system. Her effort came at a critical period during the project and is much appreciated. We also thank Andy Huttenga and Aida Novickas for their contributions in the early stages of the project. In addition, we express our appreciation to Tom Kotek for writing Appendix B and for reviewing the entire document. Finally, we thank Cathy Kaicher for her editorial assistance. 


\title{
WASTE_ACC: A COMPUTER MODEL FOR ANALYSIS OF WASTE MANAGEMENT ACCIDENTS
}

by

\author{
B.K. Nabelssi, S. Folga, E.J. Kohout, C.J. Mueller, and J. Roglans-Ribas
}

\begin{abstract}
In support of the U.S. Department of Energy's (DOE's) Waste Management Programmatic Environmental Impact Statement, Argonne National Laboratory has developed WASTE_ACC, a computational framework and integrated PC-based database system, to assess atmospheric releases from facility accidents. WASTE_ACC facilitates the many calculations for the accident analyses necessitated by the numerous combinations of waste types, waste management process technologies, facility locations, and site consolidation strategies in the waste management alternatives across the DOE complex. WASTE_ACC is a comprehensive tool that can effectively test future DOE waste management alternatives and assumptions. The computational framework can access several relational databases to calculate atmospheric releases. The databases contain throughput volumes, waste profiles, treatment process parameters, and accident data such as frequencies of initiators, conditional probabilities of subsequent events, and source term release parameters of the various waste forms under accident stresses. This report describes the computational framework and supporting databases used to conduct accident analyses and to develop source terms to assess potential health impacts that may affect on-site workers and off-site members of the public under various DOE waste management alternatives.
\end{abstract}

\section{INTRODUCTION}

The Waste Management Accident Analysis model (WASTE_ACC) is a computer system created by Argonne National Laboratory (ANL) to develop the radioactive source terms needed to assess atmospheric releases from facility accidents that might affect on-site workers and off-site members of the public under the various waste management alternatives being studied for the U.S. Department of Energy's (DOE's) Waste Management (WM) Programmatic Environmental Impact Statement (PEIS). In response to DOE guidance, the model has been developed to evaluate the spectrum of accident scenarios that could occur in the waste management activities being 
considered, facilitating a graded approach that emphasizes risk-dominant accident scenarios. WASTE_ACC provides the user with a simple tool for establishing the risk-dominant accident sequences for the many possible combinations of process technologies, waste and facility types, and management alternatives considered in the WM PEIS. Its database incorporates accident information such as frequencies of initiators, conditional probabilities of subsequent events, and source term release parameters for the various waste forms under a variety of accident stresses. The methodology applied by the WASTE_ACC system is flexible and concise, yet provides enough detail to analyze the myriad of WM PEIS alternatives and technologies.

WASTE_ACC is currently designed to interface with the WASTE_MGMT model developed at ANL to evaluate the management options for various types of DOE waste within the WM PEIS (Kotek et al. 1996). WASTE_ACC is structured to allow testing of additional waste management alternatives and assumptions in future DOE programmatic decision making. WASTE_ACC incorporates a number of sophisticated calculation features but is intended to be simple to operate. This document describes the WASTE_ACC model and its supporting databases.

\subsection{OVERVIEW OF THE WASTE_ACC MODEL}

The WASTE_ACC model is a PC-based, menu-driven computer database system used to develop source terms for operational accidents and for externally initiated accidents, such as those caused by airplane impacts or natural phenomena. Both radiological and chemical source terms can be evaluated; however, the following description pertains only to calculation of radiological source terms. A radiological source term is defined as the amount of activity (in curies) of each radionuclide released to the environment during an accident, where release is assumed to be instantaneous. For WM PEIS applications, the system used release-to-dose conversion factors (DCFs), defined as the consequence (dose) associated with a unit release of a radionuclide from a given facility and site. These factors were obtained from Oak Ridge National Laboratory (ORNL) to screen accident sequences for risk dominance. The code can also be used to provide source term parameters needed for atmospheric dispersion codes such as GENII (Napier et al. 1988) that calculate human health effects.

WASTE_ACC was designed to assess atmospheric releases from facility accidents, facilitating risk-based comparisons of WM PEIS strategies for consolidating the handling, storage, and treatment of wastes at DOE sites throughout the country. The data used by the system include waste inventories, radionuclide profiles, waste generation rates, and physical and chemical characteristics of the waste streams; associated treatment process throughputs; fractions of waste at various components of the treatment facility that can be affected in an accident; accident frequencies; and other pertinent parameters needed to calculate chemical and radiological releases (Kotek et al. 1996; Avci et al. 1994; Mueller et al. 1994). 
The model employs a probabilistic analytical approach for potential radiological accidents at DOE facilities that manage low-level waste (LLW), low-level mixed waste (LLMW), transuranic waste (TRUW), and high-level waste (HLW). The model handles both waste storage and waste treatment; treatment technologies evaluated include incineration, vitrification, and organic destruction. Both internally and externally initiated accidents are considered. Internally initiated accidents are industrial-type accidents that could occur during waste management activities (ranging from a waste drum's being dropped during handling and rendering a portion of the drum contents airborne, to a major processing accident with severe fire or explosion).

\subsection{SYSTEMS REQUIREMENTS}

The WASTE_ACC software system requires an IBM-compatible computer running MSDOS 3.3 or higher and Microsoft Windows 3.1. A microprocessor equivalent to a $486 \mathrm{SX} 33-\mathrm{MHz}$ or greater and at least $4 \mathrm{MB}$ of RAM are required. A minimum of $5 \mathrm{MB}$ of free disk space should be available prior to program installation. Input data obtained from WASTE_MGMT for WM PEIS calculations required up to $500 \mathrm{MB}$ for all alternative waste types. To run the WASTE_ACC system for all WM PEIS alternatives, a disk space of $300 \mathrm{MB}$ was required to store all intermediate output databases.

Execution of the WASTE_ACC program for WM PEIS evaluations generally took between 1 and 10 minutes on Pentium-based computers, depending on the waste type and the complexity of the WM PEIS alternative being considered. Decentralized cases generally required more computational time than centralized alternatives because of the increased number of sites that had to be analyzed, and a longer execution time was required for LLMW than for other waste types because of the large number of waste subtypes in the LLMW category.

\subsection{WASTE_ACC CAPABILITIES}

The WASTE_ACC model allows the user to:

- Determine the risk-dominant accident sequences of the WM PEIS, as a function of treatment site, management alternative, and waste type.

- Perform preliminary calculations of the radiological health effects of the postulated accident sequences for four receptors: off-site maximally exposed individual (MEI), off-site population, on-site MEI, and on-site population.

- Develop the progression of accident sequences for external initiators (such as seismic events) and calculate the probabilities of accident progression along 
the various event-tree branches using a stand-alone PC-based event-tree code (WASTE_ETA) developed at ANL.

- Print to a standard or laser printer selective records associated with the riskdominant accident sequences.

- Print to an ASCII text file the airborne release parameters and radionuclides associated with the accident sequences for final determination of the health effects.

The last feature was included to facilitate the delivery of the results of WASTE_ACC calculations to ORNL for final calculation of worker and public risks to be included in the WM PEIS document.

\subsection{CONTENTS OF THIS DOCUMENT}

This document serves as a reference for routine procedures, such as running a WM PEIS alternative case, selecting a waste type for analysis, and printing summary reports. The user is assumed to be familiar with Microsoft Windows and Microsoft FoxPro. Microsoft FoxPro is a relational database management system compatible with MS-DOS and the Windows environment. Further information on FoxPro is contained in the Microsoft Corporation booklets Microsoft FoxPro User's Guide and Microsoft FoxPro Getting Started (1989-1993).

Chapter 1 has presented the requirements and capabilities of WASTE_ACC. Chapter 2 provides a methodological overview of accident analysis through mathematical definitions of the relevant accident analysis terms and describes various accident sequences. The computational implementation is described in Chapter 3, and the user is shown how to use the model to perform an accident analysis for a WM PEIS alternative. Examples of summary reports of the results and model output are provided in Chapter 4. Improvements that would broaden the capabilities of the WASTE_ACC model for future applications are identified in Chapter 5. Details of the supporting systems used to obtain input for WASTE_ACC are provided in the appendices. 


\subsection{TECHNICAL SUPPORT}

Because WASTE_ACC is menu-driven, it is assumed that the user will not need any special training, beyond the information provided by this report, to use the system. However, technical support is available for questions that are not addressed in this document by contacting:

Dr. Charles J. Mueller

Environmental Assessment Division

Argonne National Laboratory

9700 South Cass Avenue

Building 900

Argonne, Il 60439

(708) 252-9095 or (708) 252-7071 


\section{ACCIDENT ANALYSIS METHODOLOGY}

\subsection{OVERVIEW OF WASTE MANAGEMENT ALTERNATIVES}

The WM PEIS evaluates strategies for alternative site configurations (decentralized, regionalized, or centralized) and management technologies for the treatment, storage, and disposal of DOE wastes, including HLW, TRUW, LLW, LLMW, and hazardous waste (HW). Decentralization provides for treatment and storage of wastes at the sites where they are generated, followed by disposal at a smaller number of sites throughout the country. Regionalization limits the treatment and storage of treated wastes to specific regional locations. Centralization involves the use of one or a few central sites to treat the wastes and then store them.

The primary objective of the accident analysis is to identify and calculate source terms for the risk-dominant accident sequences that could occur given the combinations of treatment and storage processes, inventories and throughputs, site locations, and site configuration alternatives defined within the WM PEIS. WASTE_ACC does this for the four waste types with radioactive components through a series of linked modules and menu-driven system.

\subsection{METHODOLOGY}

This section describes the methodology and computational framework for the facility accident analysis for the WM PEIS. Figure 1 provides an overview of the accident analysis process. As shown in the figure, the accident analysis process involves three major tasks: (1) prescreening for risk-dominant sites, facilities, and process options; (2) defining and estimating the frequencies of important accident sequences; and (3) producing the radiological source terms for these accident sequences. Implementation of this process requires identifying the risk-dominant accident sequences (considering both the likelihood and severity of plausible accidents) and generating the source term results.

\subsubsection{Material at Risk}

The calculation of the material at risk (MAR) depends on the class of accident. Three classes of accidents were considered when screening accidents and developing WM PEIS facility accident source terms for each waste type: (1) handling accidents, (2) accidents at storage facilities, and (3) accidents involving treatment processes and facilities. The MAR for a given radionuclide 


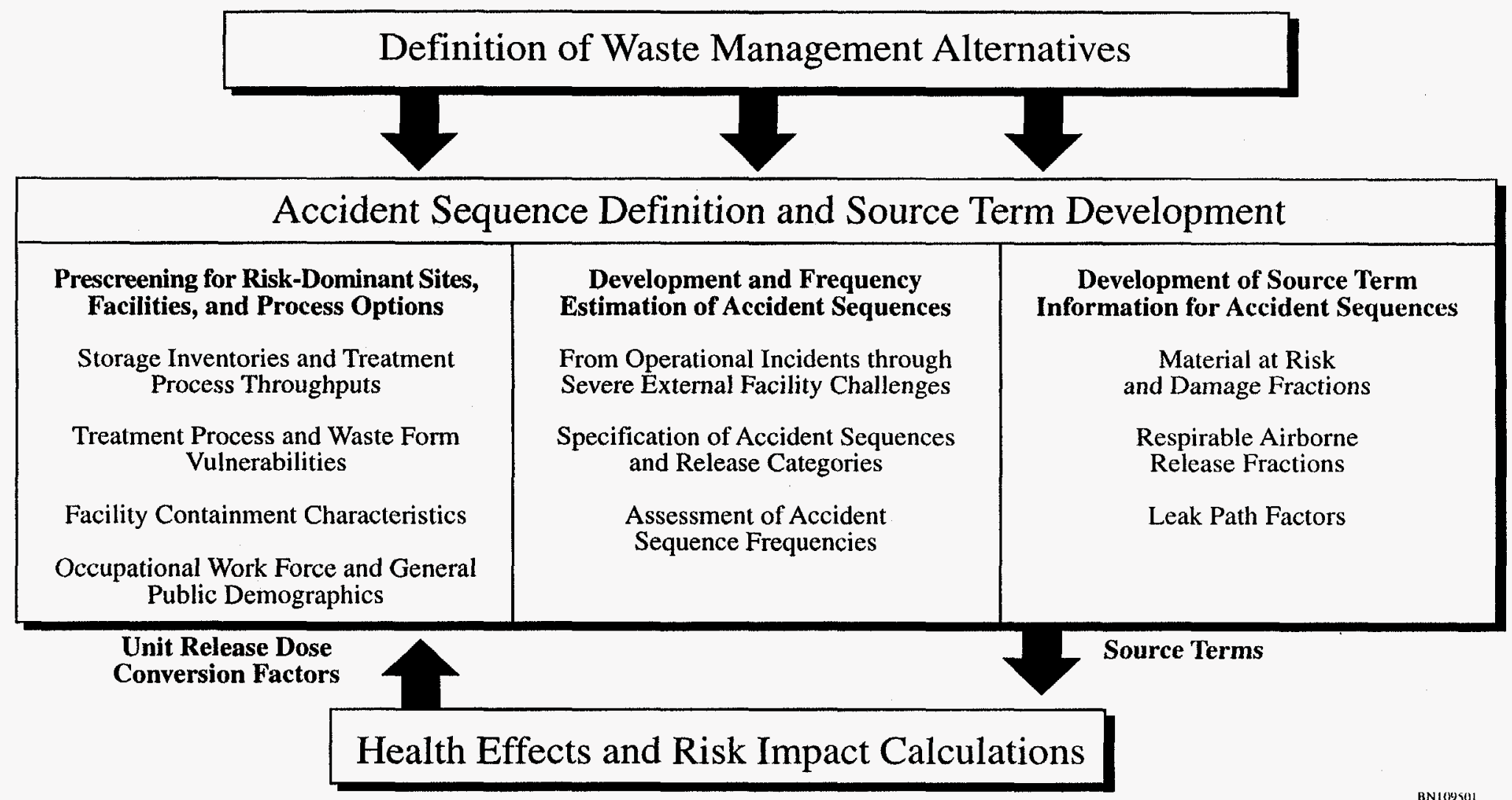

FIGURE 1 Major Components and Related Input and Output of Data for Facility Accident Analysis 
in a handling accident for waste types other than HLW is based on the assumption that the waste is contained in a 55-gal drum with a volume of $0.2 \mathrm{~m}^{3}$ :

$$
M A R_{i, d r u m}=C O N C_{i} \times V_{d r m m}
$$

where

$$
\begin{aligned}
\operatorname{CONC}_{i} & =\text { concentration of radionuclide } i \text { in waste }\left(\mathrm{Ci} / \mathrm{m}^{3}\right), \text { and } \\
V_{d r u m} & =\text { volume of a } 55-\text { gal drum }\left(0.2 \mathrm{~m}^{3}\right) .
\end{aligned}
$$

The handling accident for HLW was limited in the WM PEIS to consideration of treated HLW. It assumed the breaching of an immobilized canister from a number of causes, including a canister drop into the vault tube during transfer, drop of a cell cover on an encapsulated canister, and canister damage due to movement of the cask relative to the vault tube opening. The MAR for a given radionuclide in an HLW handling accident is taken to be the contents of one canister:

$$
M A R_{i, \text { canister }}=C O N C_{i} \times V_{\text {canister }}
$$

where

$$
V_{\text {canister }}=\text { volume of an HLW canister }\left(\text { in } \mathrm{m}^{3}\right)
$$

A full canister of HLW glass generally contains between 1,650 to $1,900 \mathrm{~kg}$ of glass (Table 1).

The calculation of MAR for a storage facility accident is estimated by the following:

$$
M A R_{i, \text { storage facility }}=\operatorname{CONC}_{i} \times V_{d r u m} \times N_{d r u m s}
$$

where

$N_{\text {drums }}=$ number of drums in the storage facility being evaluated.

Storage facility accidents (i.e., storage prior to treatment) of LLMW, LLW, and TRUW were not analyzed in the WM PEIS because the results would not help to discriminate among alternatives. This results from the underlying assumption used in the WM PEIS analyses that all sites will accumulate or at least not reduce these waste inventories for roughly 10 years, at which time 
TABLE 1 Dimensions, Weights, and Radioactivities of HLW Canisters at Selected DOE Storage Sites

\begin{tabular}{lccc}
\hline \multicolumn{1}{c}{ Variable } & WVDP & SRS & Hanford \\
\hline Outer diameter (cm) & 61 & 61 & 61 \\
Overall height (cm) & 300 & 300 & 300 \\
Material of construction & SS ${ }^{\mathrm{a}} 304 \mathrm{~L}$ & SS 304L & SS 304L \\
Nominal wall thickness (cm) & 0.34 & 0.95 & 0.95 \\
Weight (kg) & & & \\
$\quad$ Canister & 252 & 500 & 500 \\
$\quad$ Glass or ceramic & 1,900 & 1,682 & 1,650 \\
$\quad$ Total & 2,152 & 2,182 & 2,150 \\
Radioactivity per canister (Ci) & 104,300 & 234,400 & 137,000 \\
$\quad$ (January 1990) & & & \\
Decay heat per canister (W) & 311 & 709 & 389 \\
$\quad$ (January 1990) & & & \\
\hline$\quad \begin{array}{l}\text { SS = stainless steel. } \\
\text { a }\end{array}$ & & & \\
\end{tabular}

complexwide treatment will begin. Thus, all sites will achieve their maximum inventories (leading to maximum potential releases), independent of alternative.

However, early screening calculations were performed for the WM PEIS, in which generic storage facilities were assumed and the WM PEIS-defined maximum site inventory was assumed to be achieved after 10 years of accumulation and immediately prior to the initiation of treatment.

The number of drums in each facility, $N_{d r u m s}$, was varied for scoping calculations. The MAR for single drum handling and storage facility accidents is volume-weighted to reflect sitespecific average waste composition. The composition of the different waste types is described in terms of treatability categories. As an example, LLW in the WM PEIS is defined by 10 treatability categories as follows: combustible, noncombustible-noncompactible, noncombustible-compactible, metal-surface-contaminated, metal-activated, sludge/resin, aqueous, organic, remote handled, and other/special case. The treatability categories used in the WM PEIS are provided in Appendix A. The radiological activity profiles (in $\mathrm{Ci}$ ) of each treatability category and site are obtained from the WASTE_MGMT computational model (Kotek et al. 1996). Data provided by WASTE_MGMT also include current waste inventory and projected generation rates by treatability category. Appendix $B$ provides a brief description of the WASTE_MGMT code. The concentration of radionuclide $i$ in a treatability category is calculated by dividing the radionuclide activity by the treatability category inventory. 
The volume weighting of MAR for single drum and storage facility accidents is based on the generation rates of the treatability categories at each site:

$$
W_{j, k}=G R_{j, k} / \Sigma_{j} G R_{j, k}
$$

where

$$
\begin{aligned}
W_{j, k} & =\text { volume-weighting factor of treatability category } j \text { at site } k \text {, and } \\
G R_{j, k} & =\text { generation rate of treatability category } j \text { at site } k\left(\mathrm{~m}^{3} / \mathrm{yr}\right) .
\end{aligned}
$$

The summation is taken over all treatability categories, except for the aqueous waste category because aqueous waste is generally stored in large under-or above-ground tanks and not in 55-gal drums.

The calculation of MAR for a treatment facility accident takes the following form:

$$
M A R_{i, \text { treatment facility }}=T R \times C O N C_{i} \times \tau
$$

where

$$
\begin{aligned}
T R & =\text { treatment throughput rate }\left(\mathrm{m}^{3} / \mathrm{yr}\right), \text { and } \\
\tau & =\text { average residence time of MAR in treatment facility }(\mathrm{yr}) .
\end{aligned}
$$

The treatment throughput rate $\left(\mathrm{m}^{3} / \mathrm{yr}\right)$ and radionuclide activity (Ci) are obtained from the WASTE_MGMT computational model (Kotek et al. 1996) and are a function of DOE site, treatment technology, and alternative site configuration. The values of the residence time, $\tau$, were developed as a function of treatment technology (where incineration is an example of a treatment technology) from available safety documentation. The MAR for a treatment facility accident takes into account the treatment throughput for all waste substreams being processed in the facility. Thus, for a given site $k$ and alternative configuration $v$, the treatment throughput rate is the sum of the throughput rates for all the waste substreams (treatability categories) processed at the facility:

$$
T R_{k, v}=\Sigma_{j} T R_{j, k, v}
$$


where

$$
\begin{aligned}
T R_{k, v}= & \text { treatment throughput rate at site } k \text { and alternative } v\left(\mathrm{~m}^{3} / \mathrm{yr}\right), \text { and } \\
T R_{j, k, v}= & \begin{array}{l}
\text { treatment throughput rate of treatability category } j \text { at site } k \text { and } \\
\text { alternative } v\left(\mathrm{~m}^{3} / \mathrm{yr}\right) .
\end{array}
\end{aligned}
$$

\subsubsection{Source Term}

The atmospheric source term is defined as the amount of respirable airborne material released to the atmosphere from the primary confinement. The conceptual flow diagram for source term development is shown in Figure 2. The radiological source term associated with each accident is the product of four factors that vary for each radionuclide within the inventory affected by the accident:

$$
S T_{i}=M A R_{i} \times D F \times R A R F \times L P F
$$

where

$$
\begin{aligned}
S T_{i} & =\text { the source term or the atmospheric release of radionuclide } i(\mathrm{Ci}), \\
M A R_{i} & =\text { material at risk of radionuclide } i(\mathrm{Ci}), \\
D F & =\text { damage fraction (dimensionless), } \\
R A R F & =\text { respirable airborne release fraction (dimensionless), and } \\
L P F & =\text { leak path factor (dimensionless). }
\end{aligned}
$$

MAR is the total radionuclide activity in a facility with the potential of being impacted. Damage fraction (DF) is the fraction of MAR affected by the accident stresses associated in a particular accident sequence. MAR and DF are functions of the process, the facility, the accident, and the physical form of the waste.

The variable respirable airborne release fraction (RARF) refers to the fraction of the potentially available radionuclide inventory rendered airborne and in the respirable range $(<10 \mu \mathrm{m}$ aerodynamic equivalent diameter). RARF is a function of the composition of the waste, the physical properties of the radionuclides, and the accident stresses. In order to simplify the calculations, the various radionuclides are first collected into groups based on their volatilities. Except for 


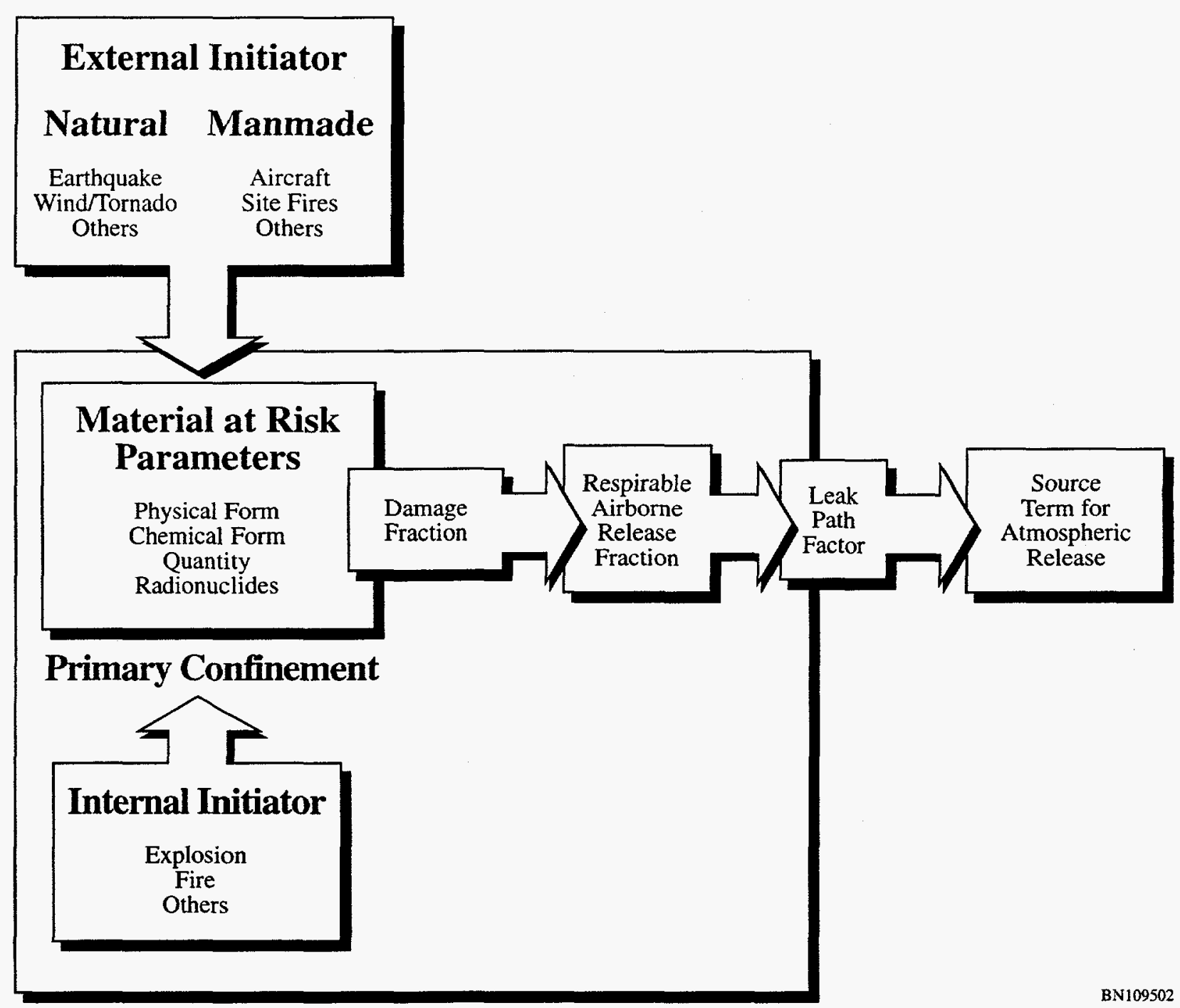

FIGURE 2 Conceptual Flow Diagram for Source Term Development

radionuclides present as noble gases and gaseous forms of halogens (e.g., $\mathrm{I}_{2}, \mathrm{CH}_{3} \mathrm{I}, \mathrm{Br}_{2}$ ), all radionuclides can be expected to form aerosols/nonvolatile solid particulates during transport in the secondary containment or after release to the atmosphere. The deposition and retention of these particulates would mainly be dependent on particle size, shape factor, particle density, and concentration, while the composition of the particulate would be of minor importance (IAEA 1992). The behavior of radionuclides releases (i.e., RARFs) is therefore reduced to the following three classes:

- Noble gases (insoluble nonreactive gases),

- Halogens (water-soluble and/or reactive gases), and

- Nonvolatile solid particulates. 
The leak path factor (LPF) is the fraction of the airborne inventory that passes through the containment barriers and filters to escape into the atmosphere. The LPF is a function of the physical form of the radionuclide (volatile vs. nonvolatile) being released and the integrity of the containment systems. In general, fairly severe accident conditions (such as natural phenomenon effects or airplane crashes) are required to defeat barriers sufficiently to provide some fraction of direct release to the environment. The code assumed that treatment modules are equipped with two banks of highefficiency particulate air (HEPA) filters. A particle collection efficiency of $99.9 \%$ (LPF of 1E-03) is assumed in the first bank, and a particle efficiency of $99.8 \%$ (LPF of 2E-03) in the second bank. Therefore, an accident that does not impact the filtration system will have an LPF of 2E-06, an accident that partially degrades the system will have an LPF of 1E-03, and an accident that causes a total failure in the system will have an LPF of 1.0. Values of RARF and LPF used in the WASTE_ACC database are generally based on the recent DOE standards published in DOE-HDBK3010-94 (DOE 1994).

\subsubsection{Consequence}

Site-specific release-to-dose conversion factors (DCFs) have been developed by ORNL to calculate radiological doses to workers and the general public resulting from unit releases of radionuclides. DCFs incorporate the atmospheric dispersion of the radionuclides as they travel from the release point to the receptors by accounting for (1) the elevation of release, (2) the distance to the nearest site-boundary, (3) the population distribution of workers and the general public at each site, and (4) the radiological characteristics of radionuclides. Exposure pathways included in DCFs are inhalation, ingestion, air immersion, and direct external exposure.

The source terms are combined with the appropriate site-specific DCFs to obtain preliminary health effects estimates (consequences). Consequences are expressed in terms of doses to various receptors, including off-site maximally exposed individual (off-site MEI), on-site MEI, on-site population (workers), and off-site population. The consequence is calculated as follows:

$$
D O S E=\Sigma_{i} S T_{i} \times D C F_{i}
$$

where

$$
\begin{aligned}
\text { DOSE }= & \text { receptor dose or consequence (rem or person-rem) summed over all } \\
& \text { radionuclides released, and } \\
D C F_{i}= & \text { release-to-dose conversion factor of radionuclide } i \text { (rem/Ci or person- } \\
& \text { rem } / \mathrm{Ci}) .
\end{aligned}
$$


In addition to individual and population doses, WASTE_ACC determines the number of increased latent cancer fatalities by multiplying the population consequences by the International Commission on Radiological Protection (ICRP)-recommended risk factors. The recommended latent cancer risk factors used in the code are 4E-04 and 5E-04 per person-rem for workers and the general public, respectively (ICRP 1991). These values are consistent with those used by the Nuclear Regulatory Commission (NRC) in its Standards for Protection Against Radiation (56 Federal Register 23363, May 21, 1991). When these cancer risk factors are applied to the individual dose, the result is the increased individual lifetime probability of latent cancer incidence.

\subsubsection{Frequency}

The accident analysis views accidents as a sequence of events characterized by a set of accident parameters (i.e., MAR, DF, RARF, and LPF). Event trees were constructed to describe postulated storage and treatment accident sequences in the WM PEIS using the WASTE_ETA computer code, which is described in Appendix $\mathrm{C}$. The available safety literature was reviewed to ensure that the accident progressions described by the various event trees were consistent with the current state of knowledge. The event trees account for the type of the initiator, the form of MAR (treatability categories), the accident stresses, and the response of the primary containment and facility to the initiator impact. The output of the event tree code is a database file containing each event tree end state (i.e., the unique accident scenario identified by the specified path through the event tree), its associated conditional probability of occurrence, the damage fraction, and associated accident stresses. A detailed description of the development of the event trees for the WM PEIS can be found in Mueller et al. (1996).

The conditional probabilities for the various accident sequences were obtained using engineering judgment to ensure consistency in the application of the information in the cited safety literature. The frequency of sequence $s$ in the event tree is calculated by multiplying the initiating frequency by the conditional probability of the sequence:

$$
F_{s}=P_{s} \times F_{\text {initiating }}
$$

where

$$
\begin{aligned}
F_{s}= & \text { frequency of sequence } s(1 / \mathrm{yr}), \\
P_{s}= & \begin{array}{l}
\text { conditional probability of sequence } s \text { (dimensionless), where the sum } \\
\text { of the conditional probabilities of the sequences for an event tree is } \\
\\
\text { one, and }
\end{array} \\
F_{\text {initiating }=} & \text { initiating frequency of the accident }(1 / \mathrm{yr}) .
\end{aligned}
$$


A lower frequency threshold (i.e., cut-off level) of $1 \mathrm{E}-07 / \mathrm{yr}$ has been applied as a criterion to determine whether the accident scenarios are physically plausible (Pinkston 1993). DOE Order 6430.1A (DOE 1989) implies a lower frequency limit of credibility of 1E-06/yr for siting considerations; a frequency lower than $1 \mathrm{E}-07 / \mathrm{yr}$ is considered so low as to be almost indeterminate or nonsensical. The same approach was used in the Final Environmental Impact Statement for Safe Interim Storage of Hanford Tank Wastes (DOE 1995a). Application of the 1E-07/yr threshold in this study has been judged sufficient to capture events with frequencies on the order of $1 \mathrm{E}-06 / \mathrm{yr}$, allowing for uncertainties and potential variability among sites in estimates of initiating frequency.

\subsubsection{Risk}

The risk for each accident sequence and site is calculated simply by multiplying the consequence of the accident sequence with the probability that the event or sequence will occur. The sequence frequency is a combination of the conditional probability of the individual accident sequence and the accident initiator frequency as shown in the previous section. The risk is thus given by:

$$
R I S K_{s}=F_{s} \times D O S E_{s}
$$

where

$$
\begin{aligned}
R I S K_{s}= & \text { risk of accident sequence } s(\mathrm{rem} / \mathrm{yr} \text { or person-rem/yr), } \\
F_{s}= & \text { frequency of accident sequence } s(1 / \mathrm{yr}), \text { and } \\
D O S E_{s}= & \text { receptor dose or consequence of accident sequence } s \text { (rem or person- } \\
& \text { rem). }
\end{aligned}
$$

For the WM PEIS, source terms for the risk-dominant sequences were transmitted to ORNL for the final health effects calculations for site workers, off-site MEI, and the general population around each site.

\subsection{DESCRIPTIONS OF POTENTIAL ACCIDENTS}

A spectrum of accident scenarios that could occur during treatment, storage, or handling activities with the chosen waste streams was developed. Generic event trees for external accident initiators (such as natural phenomena and aircraft-crash accidents) are included in the analyses for all sites and for all waste streams, although the model includes an option allowing the user to specify 
an alternative event tree to reflect more precise site-specific data. The accident sequences included in the code are briefly described in the following sections.

\subsubsection{Handling}

Handling accidents included in WASTE_ACC for LLW, LLMW, and TRUW were based on various scenarios, all involving a single drum containing waste with a representative site-specific composition (average drum). Aqueous waste is assumed not to be stored in drums and is excluded. Included in the handling accidents are spontaneous fires and explosions involving a single drum, as described in the following listing and summarized in Table 2. All single-drum accidents are assumed to result in ground releases without filtration ( $\mathrm{LPF}=1.0$ ).

- Drum Handling - The general handling accident included in the code involves the breach of a single drum, causing $25 \%$ of the drum inventory to spill and be subject to becoming airborne (DF $=0.25$ ). The probability of a handling accident occurring is $1 \mathrm{E}-04$ per handling operation. The frequency of such an accident depends on the number of handling operations per year. For a 10,000-drum facility, for example, the annual frequency is estimated at two, assuming two handling operations per drum (one for placing the drum in storage, another for retrieval for future treatment/storage/disposal). This type of accident sequence is expected to dominate the risk to workers because of the relatively high frequency of occurrence and the proximity of workers to the point of release.

- Drum Fire-A drum fire accident is assumed to be caused by a buildup of flammable gas, causing the entire contents to burn (DF $=1.0)$. The fire is assumed to be localized; the propagation of the fire to nearby drums is not considered. Because of the relatively low frequency of this event (on the order of 0.01 per year for a large site), its consequences were not considered in the WM PEIS.

- Drum Explosion-In a drum-explosion accident sequence, a drum is assumed to rupture due to overpressurization and gas buildup, causing $20 \%$ of its content to be affected ( $\mathrm{DF}=0.2)$. The explosion is assumed to be localized; the effect of explosion on nearby drums is not considered. Because of the relatively low frequency of this event (on the order of $1 \mathrm{E}-04$ per year), its consequences were not calculated in the WM PEIS.

Handling accidents for HLW were assumed to occur within the glass storage facility and involve the contents of a single immobilized canister. Due to the high stability of the HLW glass product, which is noncombustible and nonspillable, handling accidents with subsequent fire and 
TABLE 2 Single-Drum Accidents Included in WASTE_ACC

\begin{tabular}{ccl}
\hline Accident Symbol & Sequence & \multicolumn{1}{c}{ Description } \\
\hline SHA & 1 & Drum handling \\
SDF & 1 & Drum fire \\
SEX & 1 & Drum explosion \\
\hline
\end{tabular}

explosion were discounted as relatively unimportant to risk. The HLW canister accidents included in WASTE_ACC are summarized in Table 3 and discussed below. All involve a canister drop resulting in fracturing the vitrified-HLW and breaking the canister. The accident sequences differ in whether the facility filtration was assumed to be operational at the time of the accident. Because the release point of the glass canister storage facility is not greater than 2.5 times the associated building height, ground releases were assumed with both full filtration and loss of filtration. While both sequences were applied to estimate public risk, worker risk was based on unfiltered releases.

- Canister Crush, Fully Filtered - This accident considers the breach of a single HLW canister, causing the glass particles to be released from the damaged canister $(\mathrm{DF}=1.0)$ and dispersed into the facility. The majority of the glass fragments are too heavy to remain airborne, with a small fraction (1.5E-04) of the shattered glass lying within the respirable range (less than $10 \mu \mathrm{m}$ ). It is expected that the energetics of the accident would not severely degrade the facility filtration ( $\mathrm{LPF}=2 \mathrm{E}-06$ ). The total release fraction (TRF) for this accident is therefore $3 \mathrm{E}-10$ (i.e., $1.5 \mathrm{E}-04 \times 2 \mathrm{E}-06$ ). The frequency of a canister breach linearly depends on the number of handling operations per year, which is taken to be equal to the annual canister production rate. The estimated frequency for an HLW canister drop with subsequent release at the Hanford glass storage facility, which would handle 370 canisters/yr, is $4 \mathrm{E}-03 / \mathrm{yr}$ (Braun et al. 1993). The frequency of a canister breach is estimated by the following:

Frequency $\left(\mathrm{yr}^{-1}\right)=(4 \mathrm{E}-03 / \mathrm{yr}) \times$ Canister Production Rate $/ 370$

For example, the initiating frequency for a canister drop at the West Valley Demonstration Project with an assumed annual production rate of 100 canisters/yr is estimated to be $1 \mathrm{E}-03 / \mathrm{yr}$. 
TABLE 3 HLW Handling Accidents Included in WASTE_ACC

\begin{tabular}{ccl} 
Accident Symbol & Sequence & \multicolumn{1}{c}{ Description } \\
\hline GC1 & 1 & Canister crush, fully filtered \\
GC2 & 1 & Canister crush, partial filtration \\
GC3 & 1 & Canister crush, loss-of-filtration \\
\hline
\end{tabular}

- Canister Crush, Partial or Loss-of-Filtration-This accident also considers the breach of a single HLW canister that causes the glass particles to be released from the damaged canister $(\mathrm{DF}=1.0)$ and dispersed into the facility. This sequence assumes that the filtration system is unavailable at the time of the operational event $(\mathrm{LPF}=1.0)$ due to downtime for routine maintenance or equipment failure. Filter failure is expected to be more probable than containment failure for this accident sequence. Double HEPA filtration is assumed to be in place. The probability of loss of function in both banks of the filtration system after the operational event is taken to be 1E-04. The RARF for complete loss-of-filtration is $1.5 \mathrm{E}-04$, resulting in a TRF of $1.5 \mathrm{E}-04$ (RARF of 1.5E-04 $\times$ LPF of 1.0).

\subsubsection{Storage Facility}

An underlying assumption of the WM PEIS analyses is that all sites will accumulate, or at least not reduce, their inventories of waste in storage for roughly 10 years, at which time complexwide treatment of the stored wastes will begin. Thus all sites will achieve their maximum inventories independent of alternatives. In addition, recent DOE safety reports indicated that the risk from storage facility accidents should be small. For these reasons, accidents and source terms for storage facilities were not analyzed in the WM PEIS. In addition, current storage of HLW is outside the scope of the WM PEIS; therefore, accidents during HLW current storage were not considered.

However, screening calculations were used to scope the relative risks of storage facility accidents with various inventories. In these calculations, storage facilities are assumed to have minimal confinement and no credit is taken for filtration or containment integrity. The drums in the facility are assumed to contain waste with representative site-specific composition. Liquid waste is assumed not to be stored in drums and is excluded from storage facility accident analyses. The accidents considered for storage facilities are described next and summarized in Table 4 . All storage facility accidents are assumed to result in ground releases without filtration (LPF $=1.0$ ). 
TABLE 4 Storage Facility Accidents Included in WASTE_ACC

\begin{tabular}{lll}
\hline $\begin{array}{l}\text { Accident } \\
\text { Symbol }\end{array}$ & Sequence & \multicolumn{1}{c}{ Description } \\
\hline SFF & 1 & Facility fire \\
APLL & 1 & Large aircraft without release \\
APLL & 2 & Large aircraft impact with crush of containers \\
APLL & 3 & Large aircraft impact with fire \\
APLL & 4 & Large aircraft impact with fireball blast \\
APLS & 1 & Small aircraft without release \\
APLS & 2 & Small aircraft impact with crush of containers \\
APLS & 3 & Small aircraft impact with fire \\
APLS & 4 & Small aircraft impact with fireball blast \\
EQ & 1 & Earthquake without release \\
EQ & 2 & Earthquake with crush of containers \\
EQ & 3 & Earthquake with fire \\
\hline
\end{tabular}

- Fire-A facility fire accident assumes that $1 \%$ of the facility inventory will be affected $(\mathrm{DF}=0.01)$. A representative or surrogate fire was defined that was assumed to be internally initiated by a propane pipe leak, and the frequency of such an incident was estimated to be 1E-04 per year (Mueller et al. 1996). No credit is taken for mitigation measures or fire suppression systems.

- Earthquake-Seismic impacts are modeled with event trees that consider accident sequences ranging from drop and breaching of drums to significant ensuing fires in the facility. Damage fractions depend on the accident sequences. The frequency of the earthquake accident depends on the site and is based on a peak ground acceleration of $0.15 \mathrm{~g}$, where $\mathrm{g}$ is the gravitational constant.

- Aircraft Crash-Small and large aircraft impacts are modeled with event trees that consider accident sequences ranging from minor containment damage to significant fires and blast explosions in the facility. Damage fractions depend on the accident sequences. Small and large airplanes are considered separately because different levels of accident stresses can be generated by the two aircraft types. The frequency of an aircraft crash depends on the location of the site and the type of aircraft. 
The RARF applied for the source term calculation of single-drum and storage facility accidents depends on the waste type (i.e., LLW, LLMW, TRUW, or HLW) and the treatability category of the waste. Values of RARF as a function of waste type and accident stress are provided in Mueller et al. (1996).

\subsubsection{Treatment Facility}

Treatment facilities generally are assumed in the WM PEIS to have a DOE hazard category of 2 and double HEPA filtration systems. Incineration is assumed to be the treatment technology likely to dominate risk to on-site workers and the surrounding general populations.

The accident sequences considered for incineration facilities are described in the list below and summarized in Table 5 . All incineration facility accidents are assumed to be ground releases without filtration $(L P F=1.0)$, with the exception of the incinerator explosion, for which partial degradation of the filtration system is assumed $(\mathrm{LPF}=0.001)$.

- Fire-A fire in the baghouse area of the incineration facility that disperses dry ash in the filters amounting to $3 \%$ of the total ash inventory of the facility $(\mathrm{DF}=0.03)$, and in which the filtration systems fail completely. The frequency of such an accident was estimated to be 1E-03 per year (Mueller et al. 1996).

- Explosion-An incinerator explosion resulting from combustible gas buildup that disperses the dry ash in the rotary kiln at low pressure and partially degrades the filtration systems. The ash dispersed is assumed to amount to $12 \%$ of the total ash inventory of the facility $(\mathrm{DF}=0.12)$. The frequency of an explosion in the rotary kiln was estimated to be $1.5 \mathrm{E}-02$ per year (Mueller et al. 1996).

- Earthquake-Seismic impacts are modeled with event trees that consider accident sequences ranging from minor containment damage to significant ensuing fire and explosion in the facility. Damage fractions depend on the accident sequences. The initiating frequency was estimated based on the performance goal for a "moderate hazard" facility as defined in DOE guidelines.

- Aircraft Crash-Small and large aircraft impacts are modeled with event trees that consider accident sequences ranging from minor containment damage to significant ensuing fire and explosion in the facility. Damage fractions depend 
TABLE 5 Incineration Facility Accidents Included in WASTE_ACC

\begin{tabular}{lll}
$\begin{array}{c}\text { Accident } \\
\text { Symbol }\end{array}$ & Sequence & \\
\hline APLL & 1 & Large aircraft without release \\
APLL & 2 & Large aircraft with damage (vibration) of HEPA filters \\
APLL & 3 & Large aircraft impact with fire \\
APLL & 4 & Large aircraft impact with fireball blasting HEPA filters \\
APLS & 1 & Small aircraft without release \\
APLS & 2 & Small aircraft with damage (vibration) of HEPA filters \\
APLS & 3 & Small aircraft with crush impact \\
APLS & 4 & Small aircraft impact with fire \\
APLS & 5 & Small aircraft impact with fireball blasting HEPA filters \\
EQ & 1 & Earthquake without release \\
EQ & 2 & Earthquake with damage (vibration) of HEPA filters \\
EQ & 3 & Earthquake with fire \\
EQ & 4 & Earthquake with fireball blasting HEPA filters \\
IEX & 1 & Explosion in the rotary kiln \\
IFF & 1 & Fire in the baghouse area \\
\hline
\end{tabular}

on the accident sequences. Small and large airplanes are considered separately because different levels of accident stresses can be generated by the two aircraft types. The frequency of an aircraft crash depends on the site and type of aircraft.

The MAR at an incineration facility is considered to be the total ash inventory resident in the facility at the time of the postulated accident. The average residence time $(\tau)$ of MAR for an incineration facility is $0.01 \mathrm{yr}$. The RARF applied for the source term calculation is based on ash as the final form from incineration. Values of RARF for ash as a function of accident stress are given in Mueller et al. (1996).

A variety of treatment methods and processes for LLMW were considered in the WM PEIS. For difficult-to-treat LLMW containing organic material, two thermal treatment methods were analyzed: incineration, which the U.S. Environmental Protection Agency (EPA) considers the best demonstrated available technology for organic waste, and thermal desorption, which bakes the waste at temperatures lower than those used in incineration. An Alternative Organic Treatment process is being considered that replaces thermal treatment (incineration and thermal desorption) with washing and organic destruction (ORD) technologies. The safety documentation for the washing and ORD technologies was reviewed to establish which technology may significantly contribute to the overall 
risk of waste treatment. It was determined that the accident analysis would focus on ORD because of the potential for overpressurization, combustibility of the input waste stream, and energetic releases upon reactor rupture.

The accident sequences considered for ORD facilities are described in the list below and summarized in Table 6. All ORD accidents are assumed to be ground releases without filtration $(\mathrm{LPF}=1.0)$, except for the rupture of a single ORD factor (accident sequence WAX), where a stack emission and unimpaired HEPA filtration (LPF $=1.0 \mathrm{E}-06)$ is assumed; similarly, the accident sequence involving a fire in the feed mix tank (sequence WAF) is assumed to be a stack emission with partial HEPA filtration (LPF $=1.0 \mathrm{E}-03$ ). Blast or fireball effects are not included because the majority of the MAR is an aqueous liquid with organic contaminants and a fireball would not enhance the release rate.

- Rupture of a Single ORD Reactor-Rupture of a single organic destruction reactor initiated by overpressurization and/or equipment failure results in a liquid spray that flashes to steam. The damage fraction for this sequence is approximately $16.7 \%$ of the facility MAR $(\mathrm{DF}=0.167)$. The release to the atmosphere will be limited because the release is not energetic enough to breach the facility containment ( $\mathrm{LPF}=2 \mathrm{E}-06$ ). A failure rate of $1 \mathrm{E}-03 / \mathrm{yr}$ is assumed to apply to breaches of an ORD reactor that could result in significant releases.

- Feed Mix Tank Fire-A fire occurs outside the ORD feed mix tank following leakage and disperses radioactive particulates in the immediate area of the fire. The damage fraction is based on the contents of a single ORD feed mix tank (DF = 0.5). The frequency of a fire in the feed mix tank is taken to be $5 \mathrm{E}-03 / \mathrm{yr}$.

- Earthquake-The representative natural phenomenon analyzed is a seismic event because of its potential to affect the entire facility. A seismic event is postulated to rupture fittings/connections to the ORD reactors but would not result in a small fire affecting the facility MAR. Seismic impacts are modeled with event trees that consider accident sequences ranging from minor containment damage to significant fires in the facility. Damage fractions depend on the accident sequences. The initiating frequency is estimated based on the performance goal for a "moderate hazard" facility as defined in DOE guidelines.

- Aircraft Crash-Aircraft impacts are analyzed as potential manmade external events. Small and large aircraft impacts are modeled with event trees that consider accident sequences ranging from minor containment damage to 
TABLE 6 Organic Destruction Facility Accidents Included in WASTE_ACC

\begin{tabular}{|c|c|c|}
\hline $\begin{array}{l}\text { Accident } \\
\text { Symbol }\end{array}$ & Sequence & Description \\
\hline APLL & 1 & Large aircraft impact without release \\
\hline APLL & 2 & $\begin{array}{l}\text { Large aircraft impact with damage (vibration) of HEPA } \\
\text { filters }\end{array}$ \\
\hline APLL & 3 & $\begin{array}{l}\text { Large aircraft impact with overpressurization of organic } \\
\text { destruction reactor and fire affecting entire facility }\end{array}$ \\
\hline APLS & 1 & Small aircraft impact without release \\
\hline APLS & 2 & $\begin{array}{l}\text { Small aircraft impact with damage (vibration) of HEPA } \\
\text { filters }\end{array}$ \\
\hline APLS & 3 & Small aircraft impact with overpressurization of ORD reactor \\
\hline APLS & 4 & $\begin{array}{l}\text { Small aircraft impact with overpressurization of ORD reactor } \\
\text { and fire }\end{array}$ \\
\hline EQ & 1 & Small aircraft impact without release \\
\hline EQ & 2 & $\begin{array}{l}\text { Small aircraft impact with damage (vibration) of HEPA } \\
\text { filters }\end{array}$ \\
\hline $\mathrm{EQ}$ & 3 & Small aircraft impact with overpressurization of ORD reactor \\
\hline $\mathrm{EQ}$ & 4 & $\begin{array}{l}\text { Small aircraft impact with overpressurization of ORD reactor } \\
\text { and fire }\end{array}$ \\
\hline WAX & 1 & Rupture of a single ORD reactor \\
\hline WAF & 1 & Fire in the feed mix tank \\
\hline
\end{tabular}

significant fires in the facility. Small and large aircrafts are considered separately because different levels of accident stresses can be generated by the two aircraft types. It is assumed that a large aircraft crash would affect the contents of the entire facility consistent with recent safety literature concerning the postulated effect of large aircraft impacts (DOE 1995b). A small aircraft impact is assumed to affect only the ORD reactor. Aircraft accident frequencies are site dependent and were obtained from aviation statistics and the locations of DOE sites with respect to major airports and aviation routes.

The MAR of an ORD facility is considered to be the contents of the three ORD reactors and feed mix tank at the time of the postulated accident. The average residence time of MAR for an ORD facility is approximately 66 hours. Further information on the development of the MAR for an ORD facility and applicable RARF values can be found in Folga et al. (1996). 


\section{DEVELOPMENT AND USE OF THE WASTE_ACC SYSTEM}

The WASTE_ACC model was developed to automatically calculate accident source terms for the WM PEIS risk impact analyses. As such, one objective was to enable the uniform and systematic analyses of potential facility accident sequences for a spectrum of frequency classes for each alternative management strategy, focusing on risk-dominant accident sequences. Another objective was to provide the capability to rapidly compute the source terms needed to evaluate the potential human health impacts of the various alternative management strategies for LLW and LLMW inventories at approximately 50 sites, TRUW inventories at approximately 15 sites, and HLW inventories at 4 sites. A third objective was to provide a scrutable model to allow testing of additional alternatives and assumptions in future DOE programmatic decision making.

A software application was developed that incorporates several integrated modules to determine the risk-dominant accidents for each waste stream on the basis of throughput volumes and radionuclide characteristics. The output from the WASTE_MGMT computational model (Kotek et al. 1996) is used as the input for the WASTE_ACC model to predict the volumes and radionuclide concentrations of the MAR for the various alternatives. The MAR is then linked with the appropriate DCF, which is a function of site, radionuclide, release point (ground or stack release), and type of receptor (on-site MEI, off-site MEI, on-site workers, or off-site population). The accident analysis methodology and accident sequences outlined in Section 2 are generally applicable to all radioactively contaminated waste streams analyzed within the WM PEIS: HLW, TRUW, LLW, and LLMW.

Accidents are grouped into four classes on the basis of their frequency ranges, as they are traditionally considered in safety documentation: likely, unlikely, extremely unlikely, and not credible. Table 7 shows the frequency classes along with the corresponding frequency ranges. Accident sequences with frequencies below $1 \mathrm{E}-07$ per year are screened out. The accident sequences are ranked and screened on the basis of their risk contributions. Only one sequence per accident initiator, generally corresponding to the risk-dominant event, was reported for the WM PEIS. The source terms resulting from the risk-dominant sequences were transmitted to ORNL for the final health effects calculations for inclusion in the WM PEIS.

\subsection{PROGRAMMING THE WASTE_ACC SYSTEM}

The programming challenge for developing WASTE_ACC as a computer model was to construct an easy-to-use PC-based system capable of processing large amounts of data with the flexibility to accommodate various waste management alternatives, waste streams, and site-specific information. The solution was to implement an application shell, based on the Microsoft Foxpro for Windows database system. This approach has two main advantages. First, FoxPro provides software 
TABLE 7 Definitions of Accident Frequency Classes

\begin{tabular}{lll}
\hline \multicolumn{1}{c}{ Frequency Class } & Frequency Range $\left(\mathrm{yr}^{-1}\right)$ & \multicolumn{1}{c}{ Definition } \\
\hline I-Likely & $>1 \mathrm{E}-02$ & $\begin{array}{l}\text { Expected to occur once or more during } \\
\text { the lifetime of the facility. }\end{array}$ \\
II-Unlikely & $1 \mathrm{E}-04$ to $1 \mathrm{E}-02$ & $\begin{array}{l}\text { Not expected, but may occur during the } \\
\text { lifetime of the facility. }\end{array}$ \\
III-Extremely Unlikely & $1 \mathrm{E}-06$ to $1 \mathrm{E}-04$ & $\begin{array}{l}\text { Will probably not occur during the } \\
\text { lifetime of the facility. }\end{array}$ \\
IV-Not Credible & $<1 \mathrm{E}-06$ & $\begin{array}{l}\text { Has extremely low probability of } \\
\text { occurrence. }\end{array}$ \\
\hline
\end{tabular}

tools necessary to develop a Windows-based graphical interface that enables the user to easily manipulate the model. Users can provide necessary information by selecting choices in list boxes or through dialog boxes and screens. Second, by developing an application shell around the model, the several stand-alone modules that previously constituted the accident analysis system are now integrated into a single application that runs to completion at the press of a button. This has the advantage of improving the system's reliability and integrity while reducing run-time by more than $75 \%$. In addition, the application shell enables the user to run alternatives either singly or in batches.

As shown in Figure 3, the WASTE_ACC system can proceed either for a single run (to the left of the "Batch?" decision box) or for a collection of runs (to the right of the "Batch?" decision box). In either case, the process contains the "Run Model" step, which performs the actual modeling computations. Figure 4 illustrates the processing steps that sequentially occur during the "Run Model" application.

\subsection{MODULES}

As shown in Figure 4, model runs begin by setting up the workspace, which in this context means closing any files that may be open from earlier model runs. Next, the model locates the necessary input files (e.g., alternative case definitions and waste type characteristics) for the waste stream and alternative case being processed. When all the files are located, the mathematical computations begin. First, the quantity and characteristics of the MAR are computed for each site and module (i.e., handling, current storage, or treatment). One of two procedures may be used, depending on whether the run being processed is a treatment case (the methodology for calculation of the MAR for handling, storage, and treatment is given in Section 2.2.1). After the MAR file is 


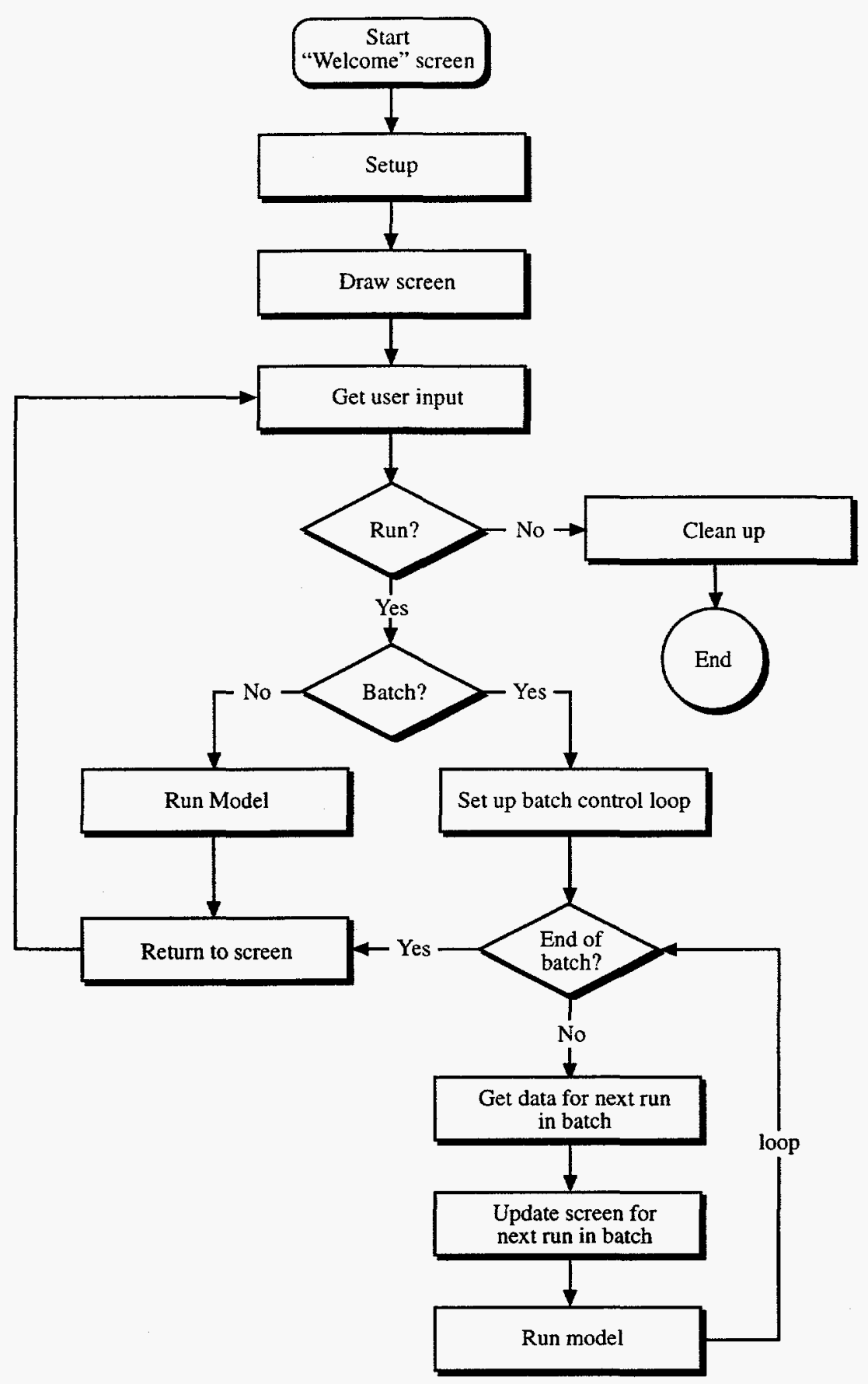

BN119504

FIGURE 3 Application Process Flow of WASTE_ACC 


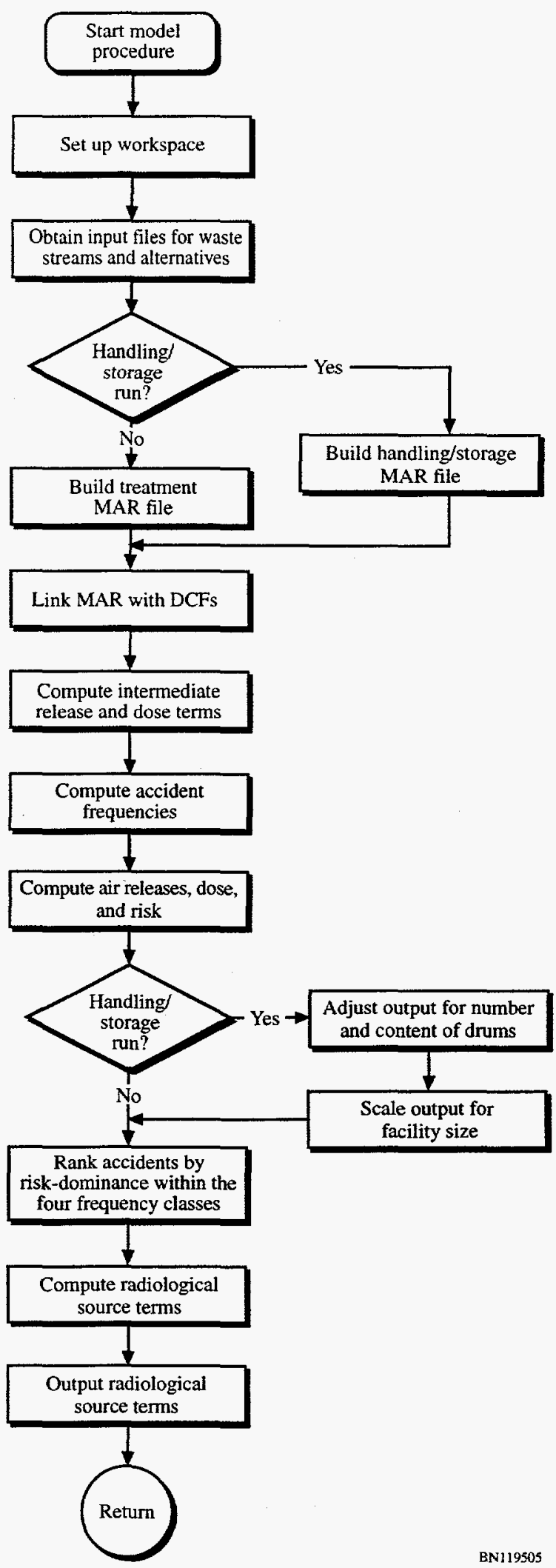

FIGURE 4 Model Implementation Flow of WASTE_ACC 
built, unit DCFs provided by ORNL are assigned based on the material's characteristics, DOE site, and receptor. The next step involves collecting the accident parameters, such as accident frequency, damage fraction, and conditional probability, that are appropriate for each accident initiator and sequence. The appropriate accident parameters are linked to the site- and module-specific MAR, and the model computes releases, frequencies, doses, risks, and consequences for all of the accident sequences. If the run is a current storage case, the results are adjusted for the number of drums and their contents. The results are then scaled according to the size of the storage facility, which is a function of the total waste inventory at each site. Finally, accident sequences are ranked by risk for the four frequency ranges, and radiological source terms for sequences with the largest impacts for each site and module are reported. At this point, the computational portion is completed, and the application returns to the main screen so the user can choose the next action.

The steps described above provide a general overview of the model's computational process. These steps occur in program modules described more fully below.

- Event Tree-The event tree module develops the externally initiated accident sequences (e.g., seismic event), assigns the damage fractions, and calculates the probabilities of accident progression along the various event tree branches. This module is a stand-alone computer code for event tree analysis of waste management accidents (WASTE_ETA). It is a PC-based version of the Experimental Breeder Reactor II Probabilistic Risk Assessment (EBR-IIPRA) event tree code that was modified for the WM PEIS to calculate the frequency of an accident sequence using branch probabilities (Roglans et al. 1993; Hill et al. 1993). WASTE_ETA requires a FORTRAN 77 compiler for execution. Output is in the form of a text file, which is automatically converted into FoxPro database format by WASTE_ACC to become the accident sequence database (ACCS). WASTE_ETA is described in Appendix C.

- Material-at-Risk-The MAR module generates the radionuclide-specific MAR based on the waste type, treatability category (physical form), module (e.g., incineration), and WM PEIS alternative being analyzed. The bases for the MAR calculations are the annual quantities and characteristics of the wastes being processed by each module generated by the WASTE_MGMT computer code as a function of DOE site. To reduce file sizes, the MAR for handling and storage modules is processed separately from that for treatment modules.

- Storage Facility Scaling-This module was used to calculate a scaling (sizing) factor for storage facilities using the projected maximum site inventories of the various waste types generated by the WASTE_MGMT 
code. The scaling factor is used to modify the MAR for storage generated in the MAR module to account for site-specific inventories. Table 8 shows one scheme developed for screening calculations. In addition, the material composition of MAR for handling and storage facility accidents are adjusted to reflect site-specific compositions.

- Atmospheric Release-The atmospheric release (source term) is a product of the MAR and the appropriate DF, RARF, and LPF, and is a function of the accident initiator, accident sequence, alternative case, waste type, and module. This calculation is performed by linking the MAR database with the accident sequence database (ACCS) and the RARF database.

- Consequence-The consequence module calculates the potential radiation dose resulting from each accident sequence by linking the atmospheric release database (produced by the atmospheric release module) with the DCF database. Preliminary health effects are calculated for four receptors: on-site MEI, off-site MEI, on-site population, and off-site population.

- Risk Calculation-The risk calculation module determines the risk (the product of the accident frequency and consequence) for each accident sequence by linking the atmospheric release database (produced by the atmospheric release module) with the DCF database, accident sequence database (ACCS), and the initiator accident frequency database (ACCF) as a function of site and module.

- Risk-Dominant Sequences-This module ranks all accident sequences and selects the risk-dominant accidents on the basis of the results of the risk calculation module. The risk-dominant sequences are grouped into the four frequency classes of Table 7 for each site and module, and the risk-dominant sequence in each frequency group is transmitted to ORNL for the final calculation of radiological doses and health effects to workers and the general public.

- Source Term Generation-Source term files for the risk-dominant accident sequences are generated, listing all radionuclides released to the atmosphere. Output is in the form of ASCII text files or FoxPro databases.

The FoxPro program modules were assembled into a FoxPro project application in Windows. The project application includes user-friendly interfaces (screens and menus) and output report writers that print the results directly in summary forms. 
TABLE 8 Storage Facility Capacity as a Function of Projected Site Inventory

\begin{tabular}{ccc}
\hline & \multicolumn{2}{c}{$\begin{array}{c}\text { Assumed Capacity of Storage } \\
\text { Facility during Accident Conditions }\end{array}$} \\
\cline { 2 - 3 } $\begin{array}{c}\text { Projected Site } \\
\text { Inventory }\left(\mathrm{m}^{3}\right)\end{array}$ & Volume $\left(\mathrm{m}^{3}\right)$ & Number of Drums \\
\hline & & \\
$>10,000$ & 5,000 & 25,000 \\
4,000 to 10,000 & 2,000 & 10,000 \\
2,000 to 4,000 & 1,000 & 5,000 \\
1,000 to 2,000 & 500 & 2,500 \\
400 to 1,000 & 200 & 1,000 \\
\hline
\end{tabular}

\subsection{INPUT DATABASES}

WASTE_ACC requires input from a number of databases: (1) storage and treatment throughputs and associated radionuclide inventory files, (2) an accident scenario file, and (3) a series of databases containing information on radionuclide, release, and dispersion characteristics. The input files required for WASTE_ACC are described next.

ALTERNTV Contains alternative case definitions for each waste type considered in the WM PEIS. The number of treatment sites is identified for each alternative. This file is accessed at the beginning of the program to allow the user to choose the alternatives to be processed and provide a brief description of the alternative. This file is common to both WASTE_ACC and WASTE_MGMT.

ACC_DESC Provides brief descriptions of all accident sequences included in the code and defines the accident symbols used in the code and displayed in the output files. Tables 2 through 6 essentially provide the content of the ACC_DESC file.

LLW_SUBC TRU_SUBC MLL_SUBC
A series of files defining the treatability categories (i.e., substreams) for each waste type. The files link the treatability category (e.g., combustible for LLW) with its unique treatability code (e.g., 01) and physical form (e.g., solid). They are used in WASTE_ACC to relate the physical characteristics of a waste form with a representative treatability category. The treatability categories and their codes are provided in Appendix A. These files are common to both WASTE_ACC and WASTE_MGMT. 
THRTxxxx

THRNXxxx

TCH_PRAM

WASTECAT
Produced by WASTE_MGMT and unique for each WM PEIS alternative case, waste type, and contamination and handling characteristic (alpha vs. non-alpha and contact-handled vs. non-contact-handled). In the WM PEIS, it is assumed that separate facilities will be used for treating alpha- and non-alphacontaminated wastes. The suffix " $x \mathrm{xxx}$ " in the file name denotes the WM PEIS alternative number and the waste type. The THRTxxxx input file contains the throughput volume rate $\left(\mathrm{m}^{3} / \mathrm{yr}\right)$ and mass $(\mathrm{kg} / \mathrm{yr})$ as functions of treatability categories and modules (e.g., current storage, vitrification, or incineration). It also includes the annual generation rates of secondary waste streams or discharges from the operation of the modules. The primary variable used by WASTE_ACC from this database is the annual volume processed or generated by each module. Records in the THRT file are uniquely identified by waste type, generating site, contamination and handling characteristics, treatability category, previous treatment technology, previous treatment technology output stream, current site, and current treatment technology. This file is used along with the THRNxxxx, WASTECAT, TCH_PRAM, and www_SUBC (where "www" refers to the waste type) databases to generate the MAR database file.

Produced by the WASTE_MGMT system and unique for each WM PEIS alternative, waste type, and contamination and handling characteristic. The suffix " $\mathrm{xxxx}$ " in the file name denotes the WM PEIS alternative number and the waste type. The primary variables used by WASTE_ACC are the radionuclide distributions and activities ( $\mathrm{Ci} / \mathrm{yr})$ associated with the treatability categories identified in THRT, as functions of the waste type, the generating site, module, treatability category, and contamination and handling characteristics (i.e., alpha vs. non-alpha and contact-handled vs. remote-handled). The information in this database is linked to the THRTxxxx file by waste type, generating site, treatment sequence, treatability category, and waste characteristics, for the development of the MAR database file.

Contains unit operation parameters (e.g., the throughput volume and mass concentration/distribution of the output product, liquid and solid residuals) for the various modules. This file is used in WASTE_ACC to assign a unique technology code to the various modules. This file is common to both WASTE_ACC and WASTE_MGMT, and is used in the development of the MAR database file.

Contains descriptions of the waste forms that occur throughout the treatment processes for all waste types and treatability categories. WASTECAT provides the relationship between the waste treatability categories (e.g., incineration product/ash) defined by the WASTE_MGMT computer code and the accident 
physical forms (e.g., noncombustible powder) used in the WASTE_ACC system for the purpose of assigning the correct RARF values. The WM PEIS accident analysis assumes the application of a single physical form to approximate the actual physical and chemical characteristics of the various treatability categories. This simplification is necessary because of the lack of information concerning the physical and chemical characteristics of the treatability categories. The WASTECAT file relates WM PEIS treatability categories to physical form categories used for accident analysis, and is used during the creation of the MAR database file.

ACCS Contains accident sequences and release stresses and conditions. Siteindependent event tree results are part of this file (event trees are used in the WM PEIS to define plausible generic accident scenarios). DFs, LPFs, and accident sequence probabilities for the modules are included for each accident sequence. Accident conditions are identified with a unique code according to the accident stress and its impact on the integrity of the secondary containment and filtration systems. ACCS is used to calculate atmospheric releases after the MAR file has been developed. The ACCS file is also used in conjunction with the ACCF file to determine the frequencies of accident sequences that are used for the risk calculation.

ACCF Contains annual frequencies of accident initiators as functions of site and module. Frequencies are provided for 52 sites and four modules, including current storage, incineration, vitrification, and organic destruction. ACCF is accessed by the code after the code has calculated the consequences (doses) for each accident sequence to calculate risk.

DCF

Contains release-to-dose conversion factors as functions of site, radionuclide, release point (ground or stack release), and type of receptor (on-site MEI, off-site MEI, on-site population, off-site population). The DCF file also identifies the radionuclide class (i.e., noble gases, halogens, and nonvolatile solids) for determination of the appropriate RARF. This file is constructed from data calculated by ORNL using the GENII code (Napier et al. 1988). The GENII code assesses doses from acute atmospheric releases of radionuclides at each site by considering the demographics of the work force and general public populations likely to be exposed to radioactive releases. Exposure pathways included in DCFs are inhalation, ingestion, air immersion, and direct external exposure. The DCF file for the WM PEIS currently contains DCF data for 139 radionuclides and 52 sites. In some instances, site-specific DCFs were not available, so generic DCFs were used. Generic DCFs were taken to be the highest available value across all sites for a particular radionuclide, release point, and 
type of receptor. Note that these generic DCFs are extremely conservative, since there may be three or four orders of magnitude difference between the lowest and highest values.

RARF

Contains RARF values for the various waste forms as a function of treatability category (e.g., noncombustible powder), accident stress, and radionuclide class (i.e., noble gases, halogens, and nonvolatile solids). The values of RARF are based on the recent DOE standards published in DOE-HDBK-3010-94 (DOE 1994). This file also contains LPF values as functions of accident stresses. The LPF values are determined by the accident stress impact on the integrity of the secondary containment and filtration systems and are dependent on radionuclide class. An LPF and RARF value of unity is assumed for radionuclides classified as noble gases and halogens, independent of the integrity of the secondary containment. The RARF file calculates atmospheric releases (source terms).

A Bachman diagram showing the related fields between the above databases is presented in Figure 5.

\subsection{USING WASTE_ACC}

Figure 6 depicts the welcome screen of WASTE_ACC. The system emphasizes an accessible user interface and high computational efficiency. A metric model run can be executed to completion at the press of a button. The next few paragraphs describe the main screen in detail and demonstrate how to use WASTE_ACC.

After clicking on the "Continue" button in the "Welcome" screen, the user proceeds to the system's main screen, presented in Figure 7.

In the top part of the screen, the user selects which waste stream and alternative to run and selects desired output options. The middle of the screen contains an area that displays which module is running so the user can monitor a run's progress. The middle also contains buttons to start model execution or to exit the program. A check box labeled "Batch" enables the user to set up a series of runs all at once. In the bottom part of the screen, users tell WASTE_ACC where to find input and where to locate working (scratch) disk space. The top part is described first.

In the first field, under the phrase "Waste Stream:," the user can select a waste stream to be analyzed via a list box. The waste stream choices include: HLW, LLW, Environmental Restoration (ER) LLW, LLMW, ER LLMW, TRUW, and ER TRUW. In the field below, labeled "Alternative:," the user selects from another list box containing the alternatives for the selected waste stream. 


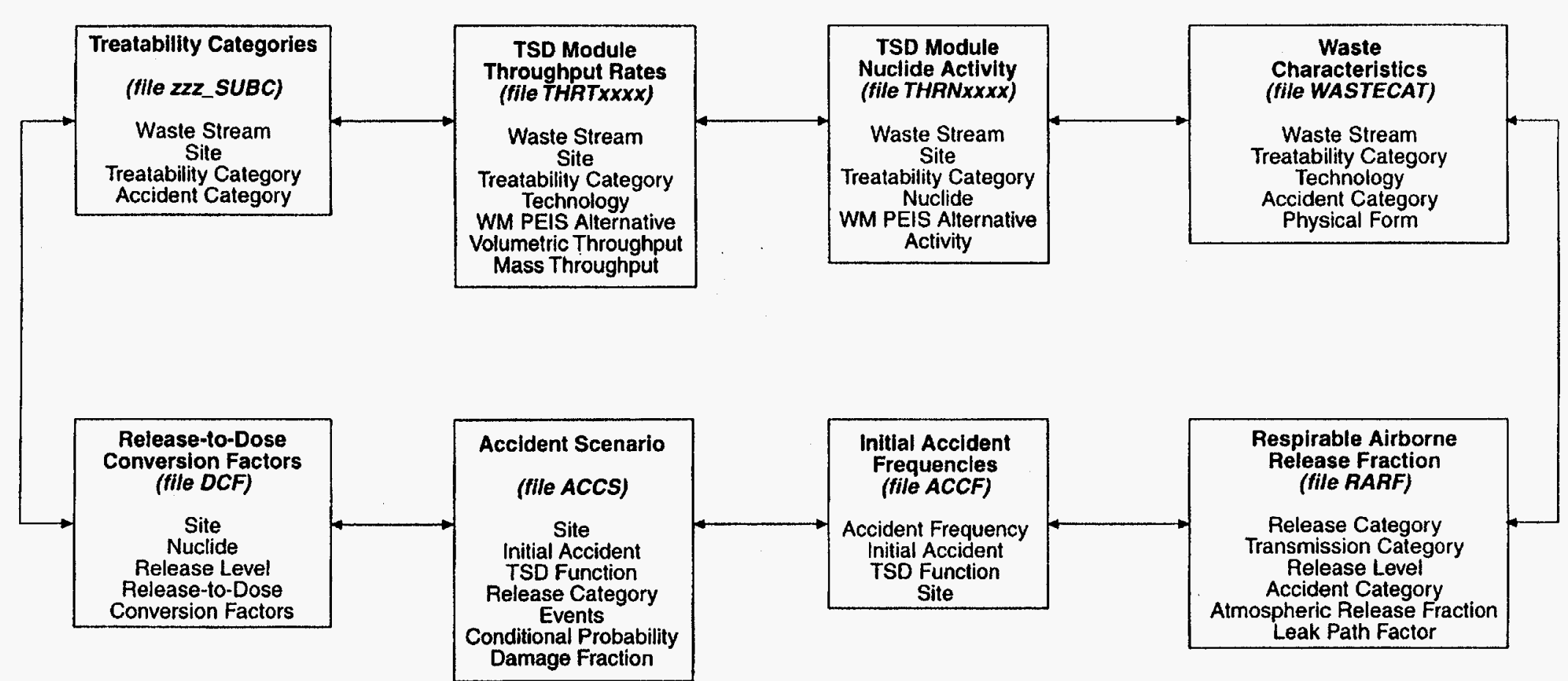

FIGURE 5 Bachman Diagram Relating to WASTE_ACC Databases 


\section{Argonne National Laboratory}

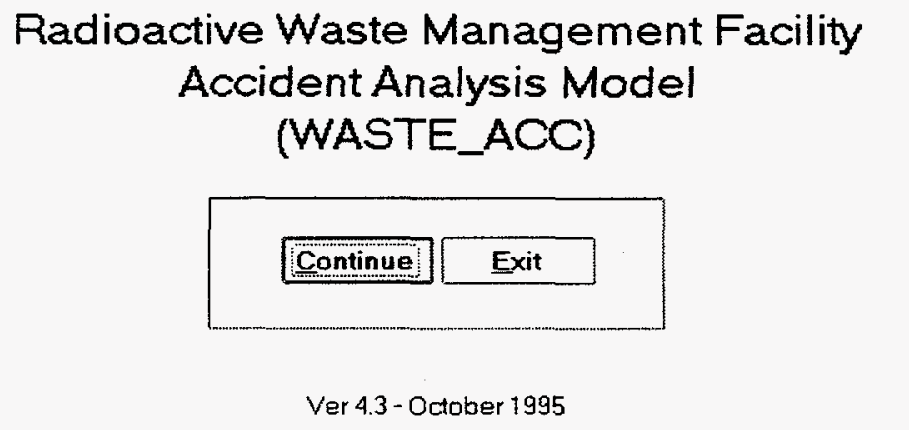

FIGURE 6 WASTE_ACC's Welcome Screen

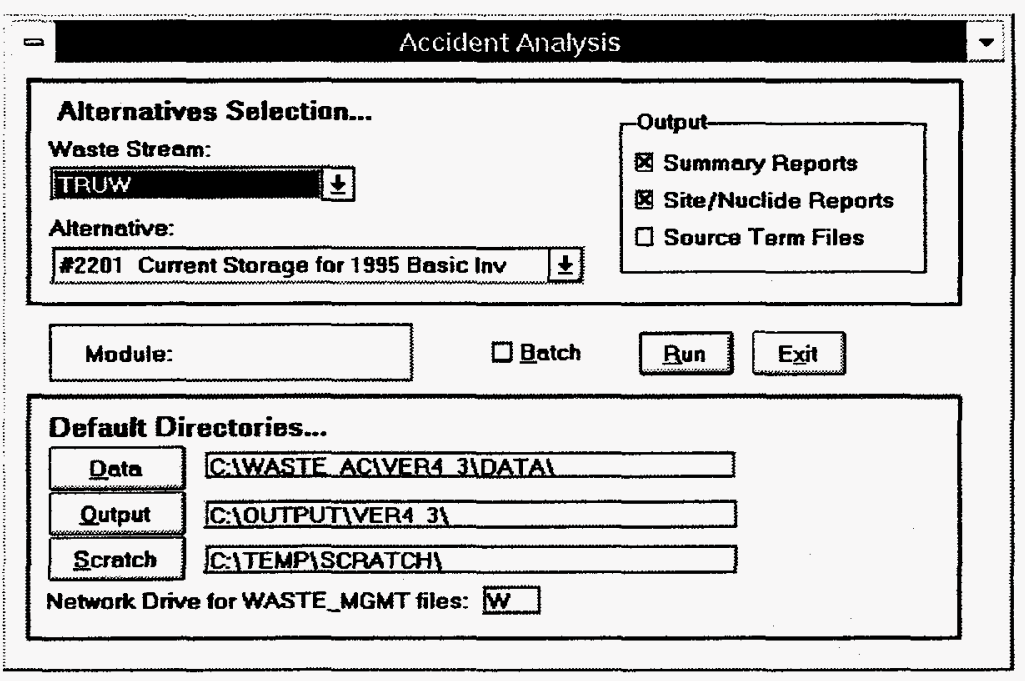

FIGURE 7 WASTE_ACC's Main Screen

After the alternative has been selected, the user can choose output options. Regardless of the options selected, WASTE_ACC always produces a summary data file that is sent to the output directory. If the "Summary Reports" check box is selected, as it is in Figure 7, then the system sends a formatted summary report to the printer and to the screen, as shown in Figure 8 . When the "Site/Nuclide Reports" check box is selected, the program prints reports that detail source terms by site and nuclide for each risk-dominant accident sequence. Finally, selecting the "Source Term Files" check box sends a source term data file to the output directory. 
Low Level Mixed Waste: Case 26

\begin{tabular}{|c|c|c|c|c|c|c|c|c|c|c|c|c|}
\hline \multicolumn{5}{|c|}{ Function: q-INCINIRATION } & \multirow[b]{2}{*}{$\begin{array}{c}\text { Sounce } \\
\text { Termu } \\
\text { (Ci) }\end{array}$} & \multicolumn{3}{|c|}{ Individual - Offsite } & \multirow[b]{2}{*}{$\begin{array}{r}\text { Frequency } \\
(y \mathrm{yr})\end{array}$} & \multirow[b]{2}{*}{$\begin{array}{l}\text { Frey. } \\
\text { uency } \\
\text { Class }\end{array}$} & \multicolumn{2}{|c|}{ Public Offisite } \\
\hline Site & bit & $\begin{array}{r}\text { VMAR } \\
(\mathbf{m} 3)\end{array}$ & $\begin{array}{r}\text { MAR } \\
\text { (Ci) }\end{array}$ & TRF & & $\begin{array}{l}\text { Dose } \\
\text { (rem) }\end{array}$ & $\begin{array}{l}\text { Cancer } \\
\text { Proba- } \\
\text { bility }\end{array}$ & $\begin{array}{r}\text { Risk } \\
\text { (rem } \\
\mathbf{y r})\end{array}$ & & & $\begin{array}{r}\text { Dose } \\
\text { (person } \\
\text {-rem) }\end{array}$ & $\begin{array}{l}\text { Cancer } \\
\text { Fatolities }\end{array}$ \\
\hline BANF & IEXI & $6.5 \mathrm{E}-05$ & $99 \mathrm{E}-03$ & $8.4 \mathrm{E}-06$ & 8.4E.08 & $2.7 \mathrm{E} .09$ & $0.0 \mathrm{E}+\infty 0$ & 4.1E-11 & 1.SE-02 & I & $8.8 \mathrm{E}-05$ & 4.4E-08 \\
\hline HANF & EQ4 & 6.5E.05 & $99 \mathrm{E}-03$ & $3.1 \mathrm{E}-04$ & $3.1 \mathrm{E}-06$ & 1.0E:07 & $1.0 \mathrm{E}-10$ & $2.5 E-12$ & 2.SE-05 & III & $3.3 \mathrm{E}-03$ & 1.7E-06 \\
\hline HANF & IFFI & 6.SE.OS & $9.95-03$ & $1.8 \mathrm{E}-06$ & $1.8 E-08$ & $5.8 E-10$ & $0.0 E+00$ & $5.8 \mathrm{E}-13$ & 1.0E-03 & II & 1.9E-OS & $95 E-09$ \\
\hline INEL & IEXI & $1.9 \mathrm{E}-01$ & $1.8 \mathrm{E}+01$ & $8.4 E-06$ & $1.6 \mathrm{E}-04$ & $7.8 \mathrm{E}-08$ & $0.0 E+\infty$ & $1.2 \mathrm{E}-09$ & 1.5E-02 & I & $9.5 E-04$ & $4.8 E-0 ?$ \\
\hline INEL & EQ4 & $1.9 \mathrm{E}-01$ & $1.8 E+01$ & $3.1 \mathrm{E}-04$ & $5.8 \mathrm{E}-03$ & $2.9 E-06$ & $1.5 \mathrm{E}-09$ & $7.3 E-11$ & 2.SE-05 & III & $3.6 \mathrm{E}-02$ & $1.8 \mathrm{E}-05$ \\
\hline INEL & IFFI & $1.9 E-01$ & $1.8 E+01$ & $1.8 \mathrm{E}-06$ & 3.3E-0S & $1.7 \mathrm{E}-08$ & $0.0 E+\infty$ & $1.7 \mathrm{E}-11$ & $1.0 \mathrm{E}-03$ & II & 2.0E-04 & 1.0E-0? \\
\hline ORNL & $\mathrm{IEX} 1$ & $1.1 \mathrm{E}-02$ & $3.0 E+\infty 0$ & $8.4 \mathrm{E}-06$ & 2.6E-05 & $5.4 \mathrm{E}-07$ & $3.0 \mathrm{E}-10$ & $8.2 \mathrm{E}-09$ & 1.5E-02 & I & $1.6 \mathrm{E} \Omega 2$ & $8.2 \mathrm{E}-06$ \\
\hline ORNL & EO4 & $1.1 \mathrm{E}-02$ & $3.0 E+\infty$ & $3.1 \mathrm{E}-04$ & $9.6 \mathrm{E}-04$ & $2.0 \mathrm{E}-05$ & $1.0 E-08$ & $5.1 \mathrm{E}-10$ & 2.5E-05 & III & $6.2 \mathrm{E}-01$ & $3.1 E-04$ \\
\hline ORNL & IFFI & $1.1 E-02$ & $3.0 \mathrm{E}+\infty 0$ & $1.8 \mathrm{E}-06$ & $5.5 \mathrm{E}-06$ & $1.2 \mathrm{E}-07$ & $1.0 \mathrm{E}-10$ & $1.2 \mathrm{E}-10$ & $1.0 \mathrm{E}-03$ & II & $35 \mathrm{E}-03$ & $18 \mathrm{E}-06$ \\
\hline SRS & IEXI & $1.4 \mathrm{E}-03$ & 1.4E-01 & $8.4 \mathrm{E}-06$ & 1.1E-06 & $1.6 \mathrm{E}-09$ & $0.0 E+\infty$ & $2.4 \mathrm{E}-11$ & $1.5 \mathrm{E}-02$ & 1 & 7.2E-0S & $3.6 E-08$ \\
\hline SRS & EQ4 & $1.4 \mathrm{E} .03$ & $1.4 E-0 !$ & $3.1 \mathrm{E}-04$ & 4.3E-0S & $6.0 \mathrm{E}-08$ & $0.0 E+\infty$ & $15 E_{-12}$ & 2.5E-05 & III & 2.7E-03 & $1.3 E-06$ \\
\hline SRS & IFFI & $1.4 \mathrm{E}-03$ & $1.4 \mathrm{E}-01$ & $1.8 \mathrm{E}-06$ & 2.5E-07 & 3.4E-10 & $0.0 E+\infty$ & $3.4 \mathrm{E}-13$ & $1.0 \mathrm{E}-03$ & II & 1.5ERS & 7.7E.09 \\
\hline
\end{tabular}

FIGURE 8 An Example of a WASTE_ACC Summary Report Screen

The user provides file location information by clicking on the appropriate button in the lower part of the screen. When the user clicks on the "Data" button, he or she is presented with a standard Windows file open dialog box. The user selects the directory to tell WASTE_ACC where to find various support and input files, except for the WASTE_MGMT data. ${ }^{1}$ Similarly, by clicking on the "Output" button, the user can tell the program where to put the output files. Note that files can be directed to any available drive, and that not all the drives need to be the same. The user can select the "Scratch," or temporary drive, where temporary files will be placed. In most cases, this should be the user's own hard drive to minimize network traffic and increase processing speed, but the extremely large capacity needed to run the model ( $>300 \mathrm{MB}$ free space) may prevent this. As an added feature, the user need not select a button to specify a drive, but may type the directory name directly into the field. Finally, the user tells the system where to find the WASTE_MGMT files by typing a drive letter next to the phrase "Network Drive for WASTE_MGMT files:." This drive may be the user's own hard drive, but due to the large size of the WASTE_MGMT files needed by WASTE_ACC (>500 MB), the drive is most likely to be that of a file server.

\subsection{PERFORMING WASTE_ACC RUNS}

WASTE_ACC has the capability to perform runs either one at a time, sequentially, or grouped together in a batch. To run a single alternative, the user simply makes the appropriate waste

1 As of Version 4.3 (October 1995). 
stream, alternative, and directory choices and then clicks the "Run" button. As the model runs, small message windows appear on the screen to indicate WASTE_ACC's progress. Besides messages, WASTE_ACC displays the name of the executing module in the main screen next to the word "Module:" to tell the user exactly which stage the model is executing. Then, when an alternative has finished processing, WASTE_ACC alerts the user with a beep and a message. The user has the option to either quit the program or make additional (sequential) model runs.

When the user must run several alternatives, he or she may elect to group them together in a "batch" run to significantly reduce processing time. To initiate a batch run, the user clicks on the "Batch" checkbox and WASTE_ACC presents them with a screen similar to that shown in Figure 9. The user chooses which alternatives to run by typing a "T" in the "T/F" (last) column of the screen. Then, when the model runs, WASTE_ACC processes all of the designated alternatives and places the resulting source term files in the output directory as specified on the main screen.

After the Run button has been clicked, WASTE_ACC begins by setting up the workspace, which in this context means closing any files that may be open from earlier model runs. Next, the system locates necessary input files for the waste stream of the scenario being processed. When all the files are located, the computations begin. First, the quantity and characteristics of the MAR are calculated. After the MAR file is built, the system assigns unit DCFs (provided by ORNL) to the MAR based on its characteristics. Next, the system develops the accident parameters, such as accident frequency, damage fraction, and conditional probability, for each site, accident initiator, and sequence. These accident parameters are then linked to the MAR and the model computes releases, doses, risks, and consequences for all of the accident sequences. Finally, the system ranks accident sequences by risk and then constructs a file to contain radiological source terms of the accident sequences with the largest risk impacts. At this point the computation is complete; if the model is

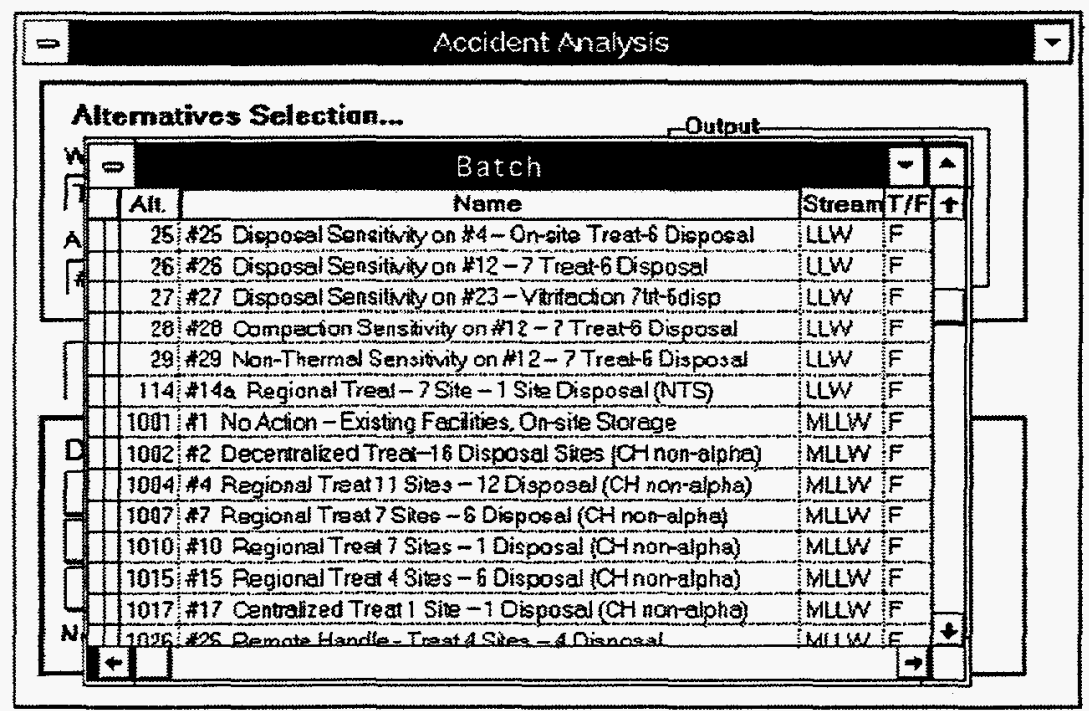

FIGURE 9 Alternative Selection for Batch Runs 
performing a single run, the application returns to the main screen so the user can choose the next action. For batch runs, the system loops through each of the selected alternatives until completed. Control then returns to the user.

If the model is processing a single run, the system displays the results in a series of report screens (see Figure 8). After all of the results have been presented, the application returns to the main screen so the user can choose the next action. For batch runs, the system does not present results on the screen because this would interrupt the program's operation. Instead, as the program loops through each of the selected alternatives, it writes the results to the output file described above. When all of the alternatives are processed, control returns to the user at the main screen.

\subsection{OUTPUT}

The final outputs of WASTE_ACC are source terms and accident summaries. Source term results include the amount of activity released to the atmosphere per radionuclide for each accident initiator. The source term results were transmitted to ORNL for the WM PEIS health effects calculations.

The accident summary results provide detailed information about the risk-dominant accidents summed over all radionuclides released, including:

- The volume of MAR (VMAR) (in $\mathrm{m}^{3}$ ),

- MAR (in Ci),

- TRF,

- Source term (in $\mathrm{Ci})$,

- Dose to the off-site MEI (in rem),

- Cancer probability for the off-site MEI,

- Risk to the off-site MEI (in rem/yr),

- Doses to off-site population (in person-rem),

- Number of excess latent cancer fatalities in off-site population, 
- Accident frequency, and

- Frequency class.

TRF is the ratio of source term to MAR, and is equal to LPF $\times$ RARF $\times$ DF. A partial listing of the accident summary is presented in Figure 8. 


\section{SAMPLE ACCIDENT ANALYSIS CALCULATION}

To demonstrate WASTE_ACC, a sample calculation is presented in Tables 9 and 10. The example shown here involves treatment facility accidents under the Centralized Alternative of TRUW management. Under this alternative, all DOE TRUW is incinerated at the Waste Isolation Pilot Plant (WIPP) in Carlsbad, New Mexico. The risk-dominant accidents, which consist of two operational (IEX and IFF sequences) and one natural phenomena (EQ sequence) initiators, are summarized in Table 9. The consequences are reported for the off-site MEI and population in terms of the radiological dose and excess cancer incidences. Table 10 shows the source terms for the riskdominant accidents, listing detailed radionuclide releases. 


\section{TABLE 9 Sample Calculation for Risk-Dominant Accidents}

\section{Transuranic Waste: Alternative 9}

\begin{tabular}{|c|c|c|c|c|c|c|c|c|c|}
\hline \multicolumn{3}{|c|}{ Function: a-INCINERATION } & \multirow[b]{2}{*}{$\begin{array}{c}\text { VMAR } \\
\left(\mathrm{m}^{3}\right)\end{array}$} & \multirow[b]{2}{*}{$\begin{array}{c}\text { MAR } \\
(\mathrm{Ci})\end{array}$} & \multirow[b]{2}{*}{ TRF } & \multirow[b]{2}{*}{$\begin{array}{c}\text { Source } \\
\text { Term } \\
(\mathrm{Ci})\end{array}$} & \multicolumn{3}{|c|}{$\begin{array}{c}\text { Maximally Exposed } \\
\text { Individual Off-Site }\end{array}$} \\
\hline Site & Init & Accident & & & & & $\begin{array}{l}\text { Dose } \\
\text { (rem) }\end{array}$ & $\begin{array}{c}\text { Cancer } \\
\text { Probability }\end{array}$ & $\begin{array}{c}\text { Risk } \\
(\mathrm{rem} / \mathrm{yr})\end{array}$ \\
\hline WIPP & EQ5 & $\begin{array}{l}\text { Earthquake with fireball } \\
\text { blasting HEPA filters }\end{array}$ & $1.9 \mathrm{E}+00$ & $5.5 \mathrm{E}+02$ & 4.6E-04 & $2.5 \mathrm{E}-01$ & $1.2 \mathrm{E}-01$ & $5.9 \mathrm{E}-05$ & $1.5 \mathrm{E}-06$ \\
\hline WIPP & IEX1 & Explosion in the rotary kiln & $1.9 \mathrm{E}+00$ & $5.5 \mathrm{E}+02$ & $8.4 \mathrm{E}-06$ & $4.6 \mathrm{E}-03$ & $2.2 \mathrm{E}-03$ & $1.1 \mathrm{E}-06$ & 3.3E-05 \\
\hline \multirow[t]{3}{*}{ WIPP } & IFF1 & Fire in the baghouse area & $1.9 \mathrm{E}+00$ & $5.5 \mathrm{E}+02$ & $1.8 \mathrm{E}-06$ & $9.9 \mathrm{E}-04$ & $4.6 \mathrm{E}-04$ & $2.3 E-07$ & $4.6 \mathrm{E}-07$ \\
\hline & & & & & \multicolumn{3}{|c|}{ Public Off-Site } & & \\
\hline & & & $\begin{array}{l}\text { Annual } \\
\text { Frequency }\end{array}$ & $\begin{array}{l}\text { Frequency } \\
\text { Class }\end{array}$ & \multicolumn{2}{|c|}{$\begin{array}{c}\text { Dose } \\
\text { (person-rem) }\end{array}$} & $\begin{array}{c}\text { Cancer } \\
\text { Fatalities } \\
\end{array}$ & & \\
\hline WIPP & EQ5 & $\begin{array}{l}\text { Earthquake with fireball } \\
\text { blasting HEPA filters }\end{array}$ & $1.2 \mathrm{E}-05$ & III & \multicolumn{2}{|c|}{$1.2 \mathrm{E}+03$} & $6.2 \mathrm{E}-01$ & & \\
\hline WIPP & IEXI & Explosion in the rotary kiln & $1.5 \mathrm{E}-02$ & I & \multicolumn{2}{|c|}{$2.3 \mathrm{E}+01$} & $1.1 \mathrm{E}-02$ & & \\
\hline WIPP & IFF1 & Fire in the baghouse area & $1.0 \mathrm{E}-03$ & II & \multicolumn{2}{|c|}{$4.9 \mathrm{E}+00$} & 2.4E-03 & & \\
\hline
\end{tabular}


TABLE 10 Sample Calculation of Source Terms for Risk-Dominant Accidents

Transuranic Waste: Alternative 9

Site: Waste Isolation Pilot Plant, Carlsbad, N.M.

Function: a-INCINERATION

\begin{tabular}{|c|c|c|c|}
\hline \multirow[b]{2}{*}{ Nuclide } & \multicolumn{3}{|c|}{ Release (Ci) } \\
\hline & EQ5 & IEX 1 & IFFI \\
\hline Ac- -227 & $1.17 \mathrm{E}-07$ & $2.14 \mathrm{E}-09$ & $4.58 \mathrm{E}-10$ \\
\hline Am-241 & $3.48 \mathrm{E}-02$ & $6.39 \mathrm{E}-04$ & $1.37 \mathrm{E}-04$ \\
\hline Am-243 & $2.01 \mathrm{E}-06$ & $3.68 \mathrm{E}-08$ & $7.88 \mathrm{E}-09$ \\
\hline $\mathrm{Cf}-252$ & $6.79 \mathrm{E}-06$ & $1.24 \mathrm{E}-07$ & $2.67 E-08$ \\
\hline $\mathrm{Cm}-244$ & $3.42 \mathrm{E}-04$ & $6.26 \mathrm{E}-06$ & $1.34 \mathrm{E}-06$ \\
\hline $\mathrm{Cm}-245$ & $3.23 \mathrm{E}-06$ & $5.93 \mathrm{E}-08$ & $1.27 \mathrm{E}-08$ \\
\hline $\mathrm{Co}-60$ & $1.73 E-05$ & $3.17 \mathrm{E}-07$ & $6.80 E-08$ \\
\hline Cs-134 & $1.94 \mathrm{E}-09$ & $3.55 \mathrm{E}-11$ & $7.61 \mathrm{E}-12$ \\
\hline Cs-137 & $1.79 \mathrm{E}-04$ & $3.27 \mathrm{E}-06$ & $7.01 \mathrm{E}-07$ \\
\hline $\mathrm{Eu}-152$ & $4.50 \mathrm{E}-08$ & $8.25 E-10$ & $1.77 \mathrm{E}-10$ \\
\hline Eu-154 & $1.90 \mathrm{E}-07$ & $3.48 \mathrm{E}-09$ & $7.45 \mathrm{E}-10$ \\
\hline Eu-155 & $2.18 \mathrm{E}-07$ & $4.00 \mathrm{E}-09$ & $8.57 \mathrm{E}-10$ \\
\hline $\mathrm{Ni}-59$ & $4.00 \mathrm{E}-14$ & $0.00 \mathrm{E}+00$ & $0.00 E+00$ \\
\hline $\mathrm{Ni}-63$ & $5.07 \mathrm{E}-12$ & $9.30 \mathrm{E}-14$ & $2.00 \mathrm{E}-14$ \\
\hline Np-237 & $8.93 E-06$ & $1.64 \mathrm{E}-07$ & $3.51 E-08$ \\
\hline $\mathrm{Pa}-231$ & $1.11 \mathrm{E}-09$ & $2.03 E-11$ & $4.36 \mathrm{E}-12$ \\
\hline $\mathrm{Pb}-210$ & $1.40 \mathrm{E}-07$ & $2.57 \mathrm{E}-09$ & $5.50 \mathrm{E}-10$ \\
\hline Pm-147 & $1.65 E-06$ & $3.03 E-08$ & $6.49 E-09$ \\
\hline $\mathrm{Pu}-238$ & $8.50 \mathrm{E}-02$ & $1.56 \mathrm{E}-03$ & $3.34 \mathrm{E}-04$ \\
\hline $\mathbf{P u}-239$ & $5.57 \mathrm{E}-02$ & $1.02 \mathrm{E}-03$ & $2.19 \mathrm{E}-04$ \\
\hline $\mathrm{Pu}-240$ & $6.37 \mathrm{E}-03$ & $1.17 \mathrm{E}-04$ & $2.50 \mathrm{E}-05$ \\
\hline $\mathbf{P u}-241$ & $6.81 E-02$ & $1.25 \mathrm{E}-03$ & $2.67 \mathrm{E}-04$ \\
\hline $\mathbf{P u}-242$ & $2.22 \mathrm{E}-04$ & $4.07 \mathrm{E}-06$ & $8.71 \mathrm{E}-07$ \\
\hline $\mathrm{Ra}-228$ & $9.61 \mathrm{E}-08$ & $1.76 \mathrm{E}-09$ & $3.77 \mathrm{E}-10$ \\
\hline $\mathrm{Sb}-125$ & $2.13 \mathrm{E}-08$ & $3.91 \mathrm{E}-10$ & $8.38 E-11$ \\
\hline Sm-151 & $2.82 \mathrm{E}-07$ & $5.17 \mathrm{E}-09$ & $1.11 \mathrm{E}-09$ \\
\hline $\mathrm{Sn}-121 \mathrm{~m}$ & $4.98 \mathrm{E}-09$ & $9.12 \mathrm{E}-11$ & $1.95 \mathrm{E}-11$ \\
\hline $\mathrm{Sr}-90$ & $1.59 \mathrm{E}-04$ & $2.92 \mathrm{E}-06$ & $6.26 \mathrm{E}-07$ \\
\hline Tc-99 & $6.76 \mathrm{E}-08$ & $1.24 E-09$ & $2.65 \mathrm{E}-10$ \\
\hline Th-229 & $4.84 E-07$ & $8.87 \mathrm{E}-09$ & $1.90 \mathrm{E}-09$ \\
\hline Th-230 & $5.77 \mathrm{E}-09$ & $1.06 \mathrm{E}-10$ & $2.27 \mathrm{E}-11$ \\
\hline $\mathrm{Th}-232$ & $1.05 E-07$ & $1.92 \mathrm{E}-09$ & $4.10 \mathrm{E}-10$ \\
\hline $\mathrm{U}-232$ & $7.02 \mathrm{E}-06$ & $1.29 \mathrm{E}-07$ & $2.76 \mathrm{E}-08$ \\
\hline U-233 & $2.90 \mathrm{E}-04$ & $5.31 \mathrm{E}-06$ & $1.14 \mathrm{E}-06$ \\
\hline $\mathrm{U}-234$ & $1.49 E-05$ & $2.73 \mathrm{E}-07$ & $5.86 \mathrm{E}-08$ \\
\hline $\mathrm{U}-235$ & $5.89 \mathrm{E}-07$ & $1.08 \mathrm{E}-08$ & $2.31 E-09$ \\
\hline $\mathrm{U}-236$ & $3.08 \mathrm{E}-10$ & $5.65 \mathrm{E}-12$ & $1.21 \mathrm{E}-12$ \\
\hline $\mathrm{U}-238$ & $1.23 \mathrm{E}-06$ & $2.25 \mathrm{E}-08$ & $4.81 E-09$ \\
\hline Total & $2.51 \mathrm{E}-01$ & 4. $60 \mathrm{E}-03$ & $9.87 \mathrm{E}-04$ \\
\hline
\end{tabular}




\section{FUTURE DEVELOPMENT}

Although much has been accomplished with WASTE_ACC in terms of establishing a computational framework and automating analyses of waste management accidents for the WM PEIS, integration issues with other WM PEIS computational tools remain. The WASTE_ACC code could be enhanced by adding the capability to compute chemical source terms. Currently, chemical source term calculations are implemented in a separate stand-alone module; however, at the time of this writing, ANL was incorporating the chemical source term module in WASTE_ACC in preparation for checking chemical source terms for the final WM PEIS.

The fragmentation of analyses for the WM PEIS was necessitated by the division of the tasks among the various organizations participating in the WM PEIS and by the tight schedules involved. As a result, WASTE_ACC is limited to the development of source terms, with risk and health effects calculated using precalculated dose conversion factors. Future work would allow WASTE_ACC to be coupled with human health effects computer codes.

Uncertainties exist in the computed values of the accident source terms and frequencies because of limitations in the completeness of the analysis, modeling accuracy, and adequacy of the parameter estimates. The uncertainties in the computed risk values need to be quantified. This can be done by propagating the probability distributions of the data through the analysis. The end result could then be presented not as a single number but as a probability distribution reflecting the certainty of these numbers.

Additional work is needed in the area of automating graphics capabilities to facilitate the evaluation of waste management alternatives across waste streams. Additionally, the code could be improved by adding help screens explaining to the user the various features of WASTE_ACC. 


\section{REFERENCES}

Avci, H., et al., 1994, "Methodology for Integrated Evaluation of Alternative Site and Treatment, Storage, and Disposal Strategies for U.S. Department of Energy Waste Management," in Proceedings of Waste Management '94, Feb. 27-March 3, 1994, Tucson, Ariz.

Braun, D.J., et al., 1993, Hanford Waste Vitrification Project Building Limited Scope Assessment, WHC-SA-1544, Westinghouse Hanford Company, Richland, Wash.

DOE: See U.S. Department of Energy.

Folga, S., et al., 1996, unpublished information, Decision and Information Sciences Division, Argonne National Laboratory, Argonne, Ill.

Hill, D.J., W.A. Ragland, and J. Roglans, 1993, "The EBR-II Probabilistic Risk Assessment: Results and Insights," in Proceedings of the International Topical Meeting on Probabilistic Safety Assessment, American Nuclear Society, La Grange Park, Ill., pp. 747-753.

IAEA (International Atomic Energy Agency), 1992, Procedures for Conducting Level 3 Probabilistic Safety Assessment of Nuclear Power Plants, Vienna, Austria.

ICRP (International Commission on Radiological Protection), 1991, 1990 International Commission on Radiological Protection, ICRP Publication 60, Pergamon Press, Oxford, England.

Kotek, T.J., et al., 1996, WASTE_MGMT: A Computer Model for Calculation of Waste Loads, Profiles, and Emissions, ANL/EAD/TM-30, Argonne National Laboratory, Argonne, Ill., Dec.

Mueller, C., et al., 1994, "Methodology and Computational Framework Used for the U.S. Department of Energy Environmental Restoration and Waste Management Programmatic Environmental Impact Statement Accident Analysis," in Proceedings of Waste Management '94, Feb. 27-March 3, 1994, Tucson, Ariz.

Mueller, C., et al., 1996, Analysis of Accident Sequences and Source Terms at Waste Treatment, Storage, and Disposal Facilities for Waste Generated by U.S. Department of Energy Waste Management Operations, ANL/EAD/TM-29, Argonne National Laboratory, Argonne, Ill., Dec.

Napier, B., et al., 1988, GENII-The Hanford Environmental Radiation Dosimetry Software System, Vols. 1 and 2, PNL-6584, UC-600, prepared by Pacific Northwest Laboratory, Richland, Wash., for the U.S. Department of Energy, Washington, D.C. 
Pinkston, D., 1993, U.S. Department of Energy Defense Programs Safety Survey Report, DOE/DP/70056-H1, U.S. Department of Energy, Washington, D.C.

Roglans, J., D.J. Hill, and W.A. Ragland, 1993, "Application of the EBR-II Probabilistic Risk Assessment," in Proceedings of the International Topical Meeting on Probabilistic Safety Assessment, PSA 93, American Nuclear Society, La Grange Park, Ill., pp. 929-935.

U.S. Department of Energy, 1989, “General Design Criteria,” DOE Order 6430.1A.

U.S. Department of Energy, 1994, Airborne Release Fractions/Rates and Respirable Fractions at DOE Nonreactor Facilities, DOE-HDBK-3010-94, Washington, D.C.

U.S. Department of Energy, 1995a, Final Environmental Impact Statement for Safe Interim Storage of Hanford Tank Wastes, DOE/EIS-0212, Richland Operations Office, Richland, Wash., Oct.

U.S. Department of Energy, 1995b, Department of Energy Programmatic Spent Nuclear Fuel Management and Idaho National Engineering Laboratory Environmental Restoration and Waste Management Programs Final Environmental Impact Statement, DOE/EIS-0203-F, Office of Environmental Management, Idaho Operations Office, April. 
APPENDIX A:

RADIOACTIVE WASTE TREATABILITY CATEGORIES 
A-2 


\section{A-3}

TABLE A.1 LLW Treatability Categories

\begin{tabular}{cl}
$\begin{array}{c}\text { Treatability } \\
\text { Code }\end{array}$ & \multicolumn{1}{c}{ Treatability Category } \\
\hline 01 & Combustible \\
02 & Noncombustible-noncompactible \\
03 & Noncombustible-compactible \\
04 & Metal-surface contaminated \\
05 & Metal-activated \\
06 & Sludge/resin \\
07 & Other/special case \\
08 & Aqueous liquid \\
09 & Organic liquid \\
10 & Remote handled \\
\hline
\end{tabular}


TABLE A.2 LLMW Treatability Categories

\begin{tabular}{cl}
$\begin{array}{c}\text { Treatability } \\
\text { Code }\end{array}$ & \multicolumn{1}{c}{ Treatability Category } \\
\hline 01 & Aqueous liquid \\
02 & Aqueous slurry \\
03 & Aqueous/halogenated organic liquid \\
04 & Aqueous/nonhalogenated organic \\
& liquid \\
05 & Halogenated organic liquid \\
06 & Nonhalogenated organic liquid \\
07 & Inorganic particulates \\
08 & Inorganic sludge \\
09 & Salt waste \\
10 & Solidified process residue \\
11 & Organic particulates \\
12 & Organic sludge \\
13 & Organic chemicals \\
14 & Category not used \\
15 & Contaminated soil \\
16 & Contaminated soil <50\% debris \\
17 & Metal debris \\
18 & Inorganic/nonmetal debris \\
19 & Combustible debris \\
20 & Heterogeneous debris \\
21 & Organic lab packs \\
22 & Aqueous lab packs \\
23 & Solid lab packs \\
\hline &
\end{tabular}


TABLE A.3 TRUW Treatability

Categories

\begin{tabular}{cl}
$\begin{array}{c}\text { Treatability } \\
\text { Code }\end{array}$ & \multicolumn{1}{c}{ Treatability Category } \\
\hline & \\
01 & Organic liquid \\
02 & Aqueous \\
03 & Organic sludges/particulates \\
04 & Inorganic sludges/particulates \\
05 & Cemented solids \\
06 & Organic debris \\
07 & Inorganic debris \\
08 & Heterogeneous debris \\
\hline
\end{tabular}


$B-1$

APPENDIX B:

WASTE_MGMT:

A COMPUTER MODEL FOR CALCULATION OF WASTE LOADS, WASTE PROFILES, AND EMISSIONS 


$$
B-2
$$


CONTENTS

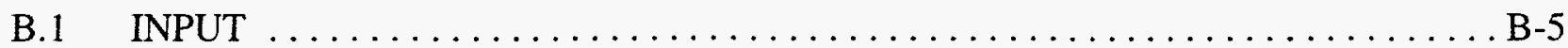

B.1.1 Waste Inventory and Characterization $\ldots \ldots \ldots \ldots \ldots \ldots \ldots \ldots \ldots \ldots \ldots \ldots \ldots$

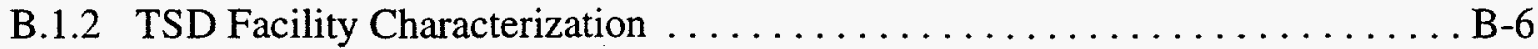

B.1.3 Alternative Definition $\ldots \ldots \ldots \ldots \ldots \ldots \ldots \ldots \ldots \ldots \ldots \ldots \ldots \ldots \ldots \ldots \ldots$

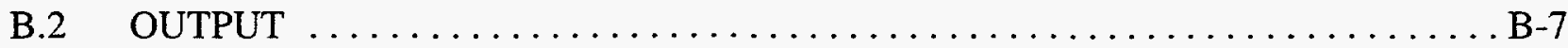

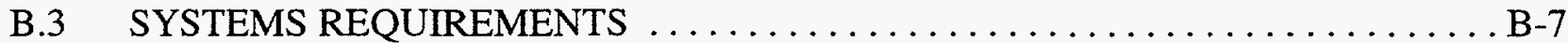




$$
\text { B-4 }
$$




\section{APPENDIX B:}

\section{WASTE_MGMT: \\ A COMPUTER MODEL FOR CALCULATION OF WASTE LOADS, WASTE PROFILES, AND EMISSIONS ${ }^{1}$}

WASTE_MGMT is a computational model that calculates waste loads, waste profiles, and emissions for the U.S. Department of Energy's Waste Management Programmatic Environmental Impact Statement (WM PEIS). The model was developed to account for the considerable variety of waste types and processing alternatives evaluated by the WM PEIS. It is table-driven with three types of fundamental waste management data as the input: (1) waste inventories and characteristics; (2) treatment, storage, and disposal (TSD) facility characteristics; and (3) definitions of alternatives. The primary outputs of the model are (1) tables of waste loads and contaminant profiles at facilities and (2) contaminant air releases for each treatment and storage facility at each TSD site for each waste stream.

\section{B.1 INPUT}

Because the computational model is used for several types of waste, the input data are specific for each waste type. However, the formats of the data, with few minor exceptions, are the same for all waste types. The three types of input data are described below.

\section{B.1.1 Waste Inventory and Characterization}

Waste inventory is identified by generating site, handling characteristic (e.g., contacthandled $[\mathrm{CH}]$ alpha), treatability category, stored volume, annual volume generation rate, and contaminant profile. The stored volume and annual generation rate are converted to an effective annual volume throughput rate, in $\mathrm{m}^{3} / \mathrm{year}$, for the model computations. The throughput rate depends on processing-alternative-specific assumptions made for the time periods of waste generation and waste processing. For example, the assumptions for low-level mixed waste (LLMW) were a 20-year generation period during which newly generated waste would be stored for the first 10 years (time required to construct new facilities), followed by a 10-year period during which all of the stored waste and newly generated waste would be processed. Waste volumes used in the model assume standardized densities for waste that is unpacked and void free. Because the waste volumes described by the input may be gross volumes that include voids in partially packed waste containers, the gross volumes are normalized to standard stream densities defined by the model.

${ }^{1}$ This appendix was written by Thomas Kotek, Environmental Assessment Division, Argonne National Laboratory. 
The waste volumes are specified separately by waste handling characteristic and waste treatability category. For example, 10 waste treatability categories have been defined for low level waste (LLW) and all LLW is considered to be either CH non-alpha waste or CH alpha waste. For comparison, 23 waste treatability categories have been defined for LLMW, which can have handling characteristics of $\mathrm{CH}$ non-alpha, $\mathrm{CH}$ alpha, remote handled (RH) non-alpha, $\mathrm{RH}$ alpha, $\mathrm{CH}$ nonalpha polychlorinated biphenyl (PCB), and $\mathrm{CH}$ alpha $\mathrm{PCB}$ waste. Contaminant profiles include both radiological distributions and hazardous material distributions, expressed as $\mathrm{Ci} / \mathrm{yr}$ by nuclide and $\mathrm{kg} / \mathrm{yr}$ by hazardous contaminant.

\section{B.1.2 TSD Facility Characterization}

Treatment technologies are described by partitioning coefficients for distributing input waste load volumes and masses among one or more output waste streams. The partitioning coefficients for waste contaminants describe the movement of contaminants among the several output streams, including air releases, and may include the destruction of organic compounds. TSD technologies can include process technologies (e.g., packaging and incineration), as well as technologies for waste storage, treated waste disposal, or treated water discharge.

The technology modules are defined by partitioning coefficients for the bulk parameters: the volume concentration or expansion of the product output stream relative to the input volume, the mass fraction of the product stream relative to the input mass, the mass fractions of secondary output streams (called residuals) relative to the input mass, and the densities of the secondary output streams. In the current model, process inputs such as fuel, water, and process additives are not explicitly incorporated in the computations. However, these factors are utilized implicitly by product volume concentrations and product mass fractions greater than unity. For some technologies, such as packaging or disposal, the treatment parameters are not specific to the treatability of the waste stream. Other technologies that are highly dependent upon the composition of the stream, such as incineration, include entries for each waste treatability category that uses the treatment.

The redistribution of contaminants during processing is specified by the fractional partitioning of the radiological contaminants and hazardous contaminants among the output streams, and of the contaminant releases to the atmosphere. The computation of the distribution of hazardous contaminants accounts for the destructive removal or complete neutralization of contaminants. For example, when organic contaminants are destroyed by incineration, the sum of the partitioning coefficients of the contaminants in the output streams is less than unity. The partitioning coefficients are the fractions of input contaminants that remain after incineration. 


\section{B.1.3 Alternative Definition}

The processing alternative definition describes the sequence of treatment technologies to be applied and the treatment and disposal locations of each inventory waste stream. The processing alternatives are defined in a single table that describes the sequence of TSD modules to be applied to the waste streams and to the originating site, the treatment site, and the disposal site. Each waste stream at a generating site is represented by one or more records that specify, by treatability and handling characteristic, the sequence of modules entered in order to arrive at a final form output (i.e., solidified treated waste, grout, or treated wastewater discharge). One record, and final form component, is created for each unique secondary output stream encountered in the treatment sequence.

\section{B.2 OUTPUT}

The primary outputs of the model are three tables that contain entries for each unique substream path traversed from the initial input until the final waste form is disposed or discharged. The file THRT contains the volume and mass of the waste substreams that are input to each TSD module. THRT also contains identifying values for the specific inventory stream (waste type, generating site, handling characteristic, and treatability), substream path (previous site, previous TSD module, previous TSD output), and current stage of processing (current site, current TSD module). Corresponding entries in file THRN contain the radiological profiles for the specific substreams and air releases of radionuclides associated with the TSD modules. For waste types that have hazardous contaminants, THRC contains the hazardous contaminant profiles of the specific waste substreams and the air releases of hazardous contaminants associated with the TSD modules. Common fields link the associated entries in files THRT, THRN, and THRC. The entries in the linking fields form unique keys that identify specific substreams in the treatment train.

\section{B.3 SYSTEMS REQUIREMENTS}

The model is implemented in Microsoft FoxPro 2.5 for MS-DOS, extended version, and consists of approximately 4,200 lines of FoxPro code with comments. An additional 2,800 lines of code were written for preparation of the model's base tables. While the minimum hardware requirements, 386SX processor and 3 Mbytes RAM, may permit execution, the current implementation using a Pentium processor with 8 Mbytes RAM required 10-15 minutes to process the complex LLMW alternatives, including generation of summary files and output listings. The relatively simple LLW alternatives are executed in times less than 1 minute. 
APPENDIX C:

WASTE_ETA:

A COMPUTER MODEL FOR EVENT TREE ANALYSIS OF WASTE MANAGEMENT ACCIDENTS 
C-2 


\section{CONTENTS}

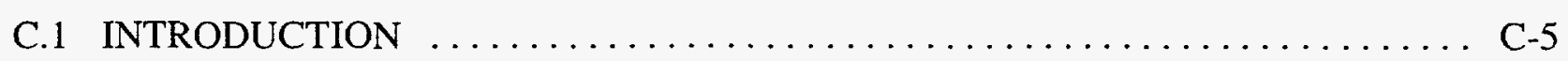

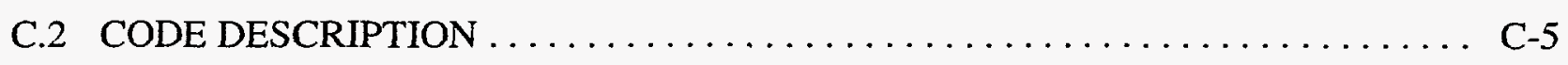

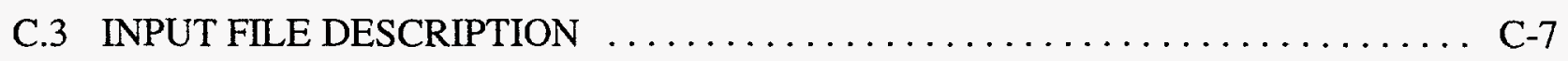

C.4 MASTER FILE DESCRIPTION $\ldots \ldots \ldots \ldots \ldots \ldots \ldots \ldots \ldots \ldots \ldots \ldots \ldots \ldots \ldots \ldots \ldots \ldots$

C.5 EXECUTION AND OUTPUT FILES $\ldots \ldots \ldots \ldots \ldots \ldots \ldots \ldots \ldots \ldots \ldots \ldots \ldots \ldots \ldots \ldots \ldots$

\section{FIGURES}

C.1 Sample Event Tree Input File in WASTE_ETA $\ldots \ldots \ldots \ldots \ldots \ldots \ldots \ldots \ldots$ C-8

C.2 Sample of a Master File Used in WASTE_ETA $\ldots \ldots \ldots \ldots \ldots \ldots \ldots \ldots \ldots$

C.3 Sample WASTE_ETA Output File: File Ready for Database

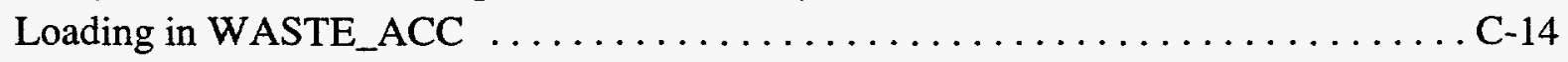

C.4 Sample WASTE_ETA Output File: Summary of Results $\ldots \ldots \ldots \ldots \ldots \ldots \ldots$ C-15

C.5 WASTE_ETA Event Tree Sample Plot $\ldots \ldots \ldots \ldots \ldots \ldots \ldots \ldots \ldots \ldots \ldots \ldots \ldots \ldots \ldots \ldots \ldots$ 
C-4 


\section{APPENDIX C:}

\section{WASTE_ETA: \\ A COMPUTER CODE FOR EVENT TREE ANALYSIS \\ OF WASTE MANAGEMENT ACCIDENTS}

\section{C.1 INTRODUCTION}

A computer code for Event Tree Analysis of Waste Management Accidents (WASTE_ETA) was adapted for the U.S. Department of Energy's Waste Management Programmatic Environmental Impact Statement (WM PEIS) from the Experimental Breeder Reactor II Probabilistic Risk Assessment (EBR-II-PRA) event tree code (Roglans et al. 1993; Hill et al. 1993). A stand-alone code, WASTE_ETA plots event trees by reading an input file rather than gathering its input from a Probabilistic Risk Assessment (PRA) database as in EBR-II-PRA. Also, the resultant accident sequence is derived from assigned branch conditional probabilities rather than the system fault trees used in the original code. In order to maintain the basic algorithm and structure of the code, the input file is maintained in approximately the same format as it is in when gathered by the original program.

The original event tree code runs on a Sun workstation, although it was developed in standard FORTRAN 77 and is portable. A DISSPLA license is required to execute the code because the graphics interface is through the DISSPLA routines. To make the WASTE_ETA available in the same platform as the rest of the modules in WASTE_ACC, WASTE_ETA graphics calls have been translated to DGE graphics calls. WASTE_ETA can be accessed from the WASTE_ACC system.

This appendix describes the capabilities and use of WASTE_ETA.

\section{C.2 CODE DESCRIPTION}

WASTE_ETA can plot an event tree and calculate the accident sequence conditional probabilities on the basis of the branch split fractions. The input and output formats and the basic structure of the program are ready for upgrading by adding a routine (such as an adaptation of the Monte Carlo scheme used in EBR-II-PRA) to perform uncertainty calculations, if desired.

The event tree can be displayed on the screen and generated as a hard copy (the PostScript plot file in the UNIX system is named std00001.dat by DISSPLA). A file with the extension .out contains a summary of the results by sequence and, if the option is added, is ready to display the probability distribution of the numerical results. A file with the extension .odb contains the event tree and sequence information needed by WASTE_ACC, and is already in a format that permits 
direct loading to the database. A utility program accessed from the interactive menus performs the database loading operation.

Information about the event tree structure is provided in an input file. The branch point split-fraction information is obtained from a secondary input file (referred to as the master file), and the initiating event and top event data are provided either in the main input file or in the master file. The master file was created in order to provide a unique repository for the initiating event, the top event, and the split fraction information, given that in the WM PEIS the same top events are used in many event trees. Having all of the initiating events, top events, and split fractions in a single file (which in the future may be stored in WASTE_ACC) is desirable for quality assurance and ensures consistency in approach.

The user can select, through the input file, the following options when executing WASTE_ETA:

- Plot the event tree only. The code will ignore the split fractions and will not calculate conditional probabilities.

- Bypass the calculation of sequence probabilities and print sequence probabilities read from the input file.

- Select the initiating event frequency to be read from the master file or alternatively assumed to equal 1 . In the first case, the code will calculate the sequence frequency. If the initiating event frequency is assumed to be 1 , the sequence conditional probability will be calculated.

- Provide the descriptions of the initiating and the top events in the input file instead of gathering them from the master file.

- Provide the name of the master file to be used, when applicable. The user can specify different master files (e.g., for comparison purposes) or not use a master file at all.

The event tree code is run interactively. The user supplies only two pieces of information:

- The name of the input file.

- Specification to display the event tree on the screen or store it in a file for printing. The user input is limited to $Y$ (screen display) or $N$ (file storage). 


\section{C.3 INPUT FILE DESCRIPTION}

The event tree input file must be generated by the user. An input file can contain data for one

event tree only. Figure C. 1 is an example of an event tree input file. The input is described by line below.

LINE 1 Information about the WM PEIS alternative.

Field 1: Waste type

Field 2: DOE site

Field 3: Facility name

Field 4: Facility function

Format: $\quad \mathrm{A} 6,1 \mathrm{X}, \mathrm{A} 20,1 \mathrm{X}, \mathrm{A} 20,1 \mathrm{X}, \mathrm{A} 20$

LINE 2 User options for the event tree code execution.

Field 1: Option to get information from master file

$0-$ no

1 - yes

Field 2: Number of top events in the event tree (maximum of 12)

Field 3: Number of sequences in the event tree (maximum of 25)

Field 4: Option for frequency calculations

0 - no

1 - yes

2 - frequency values in input file

Field 5: Option for uncertainty calculations

0 - no

1 - yes (not available yet)

Field 6: Option for initiating event frequency

0 - get frequency from master file

1 - assume frequency is equal to 1.0

Field 7: Name of the master file, if any

Format: $\quad \mathrm{I} 1,1 \mathrm{X}, \mathrm{I} 2,1 \mathrm{X}, \mathrm{I} 2,1 \mathrm{X}, \mathrm{I} 1,1 \mathrm{X}, \mathrm{I} 1,1 \mathrm{X}, \mathrm{I} 1,1 \mathrm{X}, \mathrm{A} 30$ 


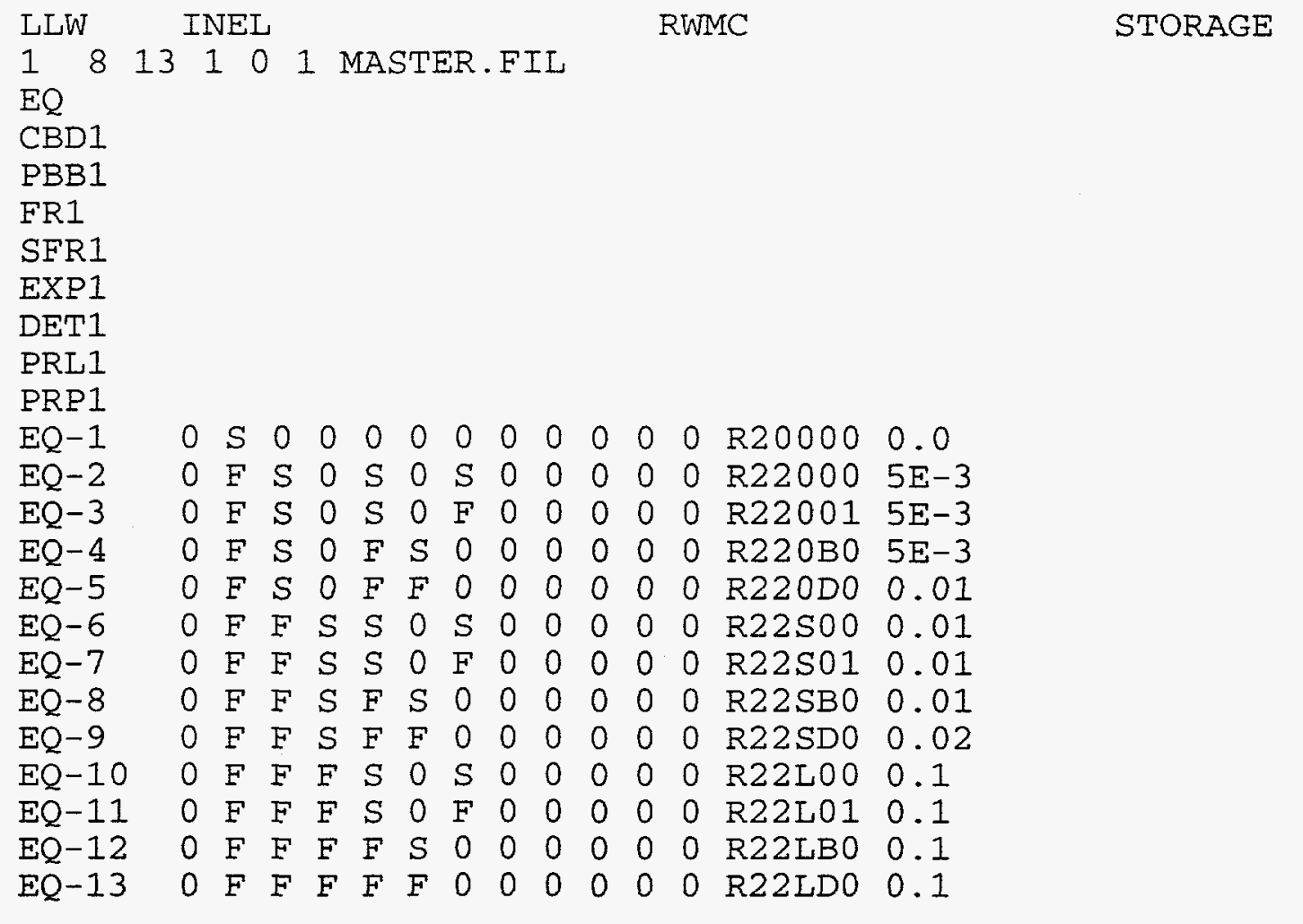

FIGURE C.1 Sample Event Tree Input File in WASTE_ETA

LINE 3 Name and description (optional) of the initiating event. The description is supplied only when no information is to be read from the master file.

Field 1: Initiating event name (acronym)

Field 2: Initiating event description-optional

Format: $\mathrm{A} 8,1 \mathrm{X}, \mathrm{A} 60$

LINE 4 Name and description (optional) of an event tree top event. The description is supplied only when no information is to be read from the master file.

Field 1: Top event name (acronym)

Field 2: Top event description-optional

Format: $\quad \mathrm{A} 8,1 \mathrm{X}, \mathrm{A} 72$

Repeat line 4 as many times as there are top events in the event tree. 
LINE 5 Accident sequence description. The first 15 fields must be provided, but the last field, sequence frequency, is only required when event tree frequencies will be displayed but the calculations will not be performed.

Field 1: $\quad$ Accident sequence name (acronym).

Fields 2-13: Event tree branching description. Each of the 12 fields contains the status of the top events for the sequence. If the sequence represents a top event in a successful status, an $S$ is entered. If the top event is in a failed status, an $F$ is entered. Otherwise, the field should display a $O$. Note: by convention, a success branch is the upper branch in the event tree bifurcation.

Field 14: Atmospheric release class acronym.

Field 15: Damage ratio. Although entered as a character, it will be treated as a numerical field in FoxPro. The string (limited to four characters) can be entered in exponential form (e.g., 0.01 or 1E-2).

Field 16: Sequence frequency-optional.

Format: $\quad \mathrm{A} 12,1 \mathrm{X}, 12(\mathrm{~A} 1,1 \mathrm{X}), \mathrm{A} 6,1 \mathrm{X}, \mathrm{A} 4,1 \mathrm{X}, \mathrm{E} 10.3$

Repeat line 5 as many times as there are accident sequences in the event tree.

\section{C.4 MASTER FILE DESCRIPTION}

The master file is a unique repository of initiating event definitions, top event definitions, and split fractions (conditional probabilities). The same definitions and probabilities are used in several event trees; centralizing the common information provides more convenience and quality assurance. A sample of a master file is shown in Figure C.2. The master file contains the following information:

- Initiating Events-Definitions of initiating event acronyms and frequency distribution information (mean value, measure of dispersion, and distribution type). The frequency information is not used in general. The frequency is normally assumed to be 1.0 because the initiating event frequencies are stored elsewhere in the WASTE_ACC database. The distribution information will not be used until the uncertainty calculation capabilities are added to the code. 


\begin{tabular}{|c|c|c|c|c|}
\hline VOL & Volcanic Activity (Ashes or Lava Flows) & & 1.0 & 1.L \\
\hline WT & Wind/Tornado - Generic Facility with Combustibles & & 1.0 & 1.L \\
\hline APLS & Small Aircraft Impact on the Facility & & 1.0 & 1.L \\
\hline APLL & Large Aircraft Impact on the Facility & & 1.0 & $1 . L$ \\
\hline$E Q$ & Seismic Event Beyond Design Basis & & 1.0 & 1.L \\
\hline HAN & Handling Accident & & 1.0 & 1.L \\
\hline CBD1 & Integrity of Secondary (Building) Containment & & 1.0 & 1. L \\
\hline CBD2 & Integrity of Secondary (Building) Containment & & 0.1 & 1. L \\
\hline CBD3 & Integrity of Secondary (Building) Containment & & 0.5 & 1.L \\
\hline PBB1 & Integrity of Primary (Canister) Containment & & 0.2 & 1. L \\
\hline PBB2 & Integrity of Primary (Canister) Containment & & 0.9 & 1. L \\
\hline PBB3 & Integrity of Primary (Canister) Containment & & 0.99 & 1. L \\
\hline PBB4 & Integrity of Primary (Canister) Containment & & 0.5 & 1.L \\
\hline PBB5 & Integrity of Primary (Canister) Containment & & 0.1 & 1.L \\
\hline FR1 & Fire Involving Waste & & 0.1 & 1.L \\
\hline FR2 & Fire Involving Waste & & 1.0 & 1. L \\
\hline SFR1 & Fire Severity & & 0.1 & 1.L \\
\hline SFR2 & Fire severity & & 1.0 & 1.L \\
\hline SFR3 & Fire Severity & & 0.2 & $1 . \bar{L}$ \\
\hline EXP1 & Explosion Involving Waste & $<5$ & $1.0 \mathrm{E}-4$ & 1. L \\
\hline EXP1 & Explosion Involving Waste & $6,7,8,9$ & $1.0 \mathrm{E}-3$ & 1. L \\
\hline EXP1 & Explosion Involving Waste & $>10$ & 1. $0 \mathrm{E}-2$ & 1.L \\
\hline EXP2 & Explosion Involving Waste & & 0.1 & 1.L \\
\hline EXP3 & Explosion Involving Waste & & 0.5 & 1. L \\
\hline DET1 & Explosion Severity & $<5$ & $1.0 \mathrm{E}-3$ & 1.L \\
\hline DET1 & Explosion Severity & $6,7,8,9$ & $1.0 \mathrm{E}-2$ & $1 . L$ \\
\hline DET1 & Explosion Severity & $>10$ & 0.1 & 1.L \\
\hline DET2 & Explosion Severity & & 0.1 & 1.L \\
\hline PRL1 & Pressurized Release & & 0.1 & $1 . L$ \\
\hline PRL2 & Pressurized Release & & 0.01 & 1.L \\
\hline PRP1 & Propagation of Accident to Waste in Next Area & & 1.0 & 1. L \\
\hline PRP2 & Propagation of Accident to Waste in Next Area & & 0.01 & 1. L \\
\hline PRP3 & Propagation of Accident to waste in Next Area & & 0.1 & 1. L \\
\hline FLT1 & Filtered Exhaust system Operable & & 0.1 & $1 . \bar{L}$ \\
\hline
\end{tabular}

FIGURE C.2 Sample of a Master File Used in WASTE_ETA 
- Top Event Information-Definitions of top events, followed by their usage in the sequence and conditional probability information (mean, dispersion, and distribution type). Because the uncertainty calculations are not available, only the mean values of the conditional probabilities are used. The specific conditional probability of the sequence usage is provided because the same top event can assume different conditional probabilities in the same event tree depending on the previous accident evolution. For example, the conditional probabilities will be different from explosion top event whether or not a fire has occurred, thus assuming different values in different sequences.

Each line in the master file contains the information for either an initiating event or a top event. Initiating events and top events can be listed in any order. Each line contains up to six fields:

Field 1: The initiating event or top event name (acronym).

Field 2: Description of the initiating event or top event.

Field 3: Sequence usage for a top event frequency entry. This field is only used when needed for top events. Some top events in the same event tree can have different conditional probabilities for different sequences. This field specifies the sequences to which a particular conditional probability applies. If this field is left blank, the code assumes that the same top event conditional probability applies to all sequences in the event tree. The sequences corresponding to a particular conditional probability are specified by sequence number in the event tree. The following characters are valid:

$$
\begin{array}{ll}
<n & \text { Sequence number less than or equal to } n \\
n, m, l & \text { Sequence numbers } n, m \text {, and } I \\
>n & \text { Sequence number greater than or equal to } n
\end{array}
$$

For example, if top event EXP is used in the same event tree with three different conditional probabilities $(0.1$ for sequences $1-5$, 0.2 for sequences $6-9$, and 0.3 for sequences 10-15), the following entries would be made in the master file (in the proper format):

$\begin{array}{llll}\text { EXP }^{2} & \text { Explosion event } & <5 & 0.1 \\ \text { EXP } & \text { Explosion event } & 6,7,8,9 & 0.2 \\ \text { EXP } & \text { Explosion event } & >10 & 0.3\end{array}$

${ }^{2}$ Note: Because the same top events are used with different conditional probabilities in many event trees, a convention of appending a digit to the top event acronym has been used in the WM PEIS (e.g., EXPn has become the top event name in order to have unique entries in the master file for each different conditional probability associated with the top event EXP). 
Field 4: The initiating event frequency or the top event conditional probability (mean value).

Field 5: The measure of dispersion associated with the initiating event frequency (or the top event conditional probability) distribution. This parameter is to be used in uncertainty calculations, when available. Currently, any value can be entered.

Field 6: The initiating event frequency (or top event conditional probability) distribution ( $L$ for lognormal, $N$ for normal, etc.). This parameter is to be used in uncertainty calculations, when available. Currently, any value can be entered.

Formats:

Initiating Events: $\mathrm{A} 8,1 \mathrm{X}, \mathrm{A} 60,44 \mathrm{X}, \mathrm{E} 10.3,1 \mathrm{X}, \mathrm{F} 4.1,1 \mathrm{X}, \mathrm{A} 1$

Top Events: $\quad$ A8, 1X, A72, 1X, A30, 1X, E10.3, 1X, F4.1, 1X, A1

\section{C.5 EXECUTION AND OUTPUT FILES}

The PC version of WASTE_ETA is currently stored in the WM PEIS Accident Analysis computer:
c: IpubliclaccdIWASTE_ETA.for
c:IpubliclaccdIWASTE_ETA.exe

The code can be executed from the interactive menus in WASTE_ACC.

When the input file defining the event tree and the master file (if it is used) are complete, the code can be executed. The user provides the name of the input file. If the master file is used, its name appears in the input file. The user then chooses to view the event tree on the screen and/or to create a file containing the plot. In addition to the plot file, two additional files are created:

\section{input_file_name.odb \\ input_file_name.out}

The first file contains the output from the event tree in a format ready for loading to the accident analysis database, and the second file contains a summary of the results (already prepared for uncertainty results) and any error or warning messages that may have been generated during the execution. 
The information can be loaded into the WASTE_ACC database by executing a program accessed from the interactive menus in FoxPro. Note that FoxPro stores every table in a different system file. It is therefore suggested that, for each waste type in the WM PEIS, all the event tree .odb output files be merged into a single file before being loaded into the database. In this way, all the event tree information for the same waste type will be stored in the same FoxPro database file.

Sample output files are given in Figures C. 3 to C.5. Figure C. 3 shows the database-ready file, Figure C. 4 shows the results summary file, and Figure C. 5 shows the event tree plot. These output files are generated by executing WASTE_ETA with the input file shown in Figure C.1 and the master file in Figure C.2. 
LLW INEL RWMC STORAGE EQ $110.800 \mathrm{E}+00 \quad 0.0$ NONE R20000

LLW INEL RWMC STORAGE EQ $20.162 \mathrm{E}+00 \quad 5 \mathrm{E}-3$ PBB1 R22000

LLW INEL RWMC STORAGE EQ 3 0.180E-01 5E-3 PBB1-PRL1 R22001

LLW INEL RWMC STORAGE EQ 4 0.180E-04 5E-3 PBB1-EXP1 R220B0

LLW INEL RWMC STORAGE EO $50.180 \mathrm{E}-07$ 0.01 PBB1-EXP1-DET1 R220DO

LLW INEL RWMC STORAGE EQ $60.162 \mathrm{E}-010.01$ PBB1-FR1 R22S00

LLW INEL RWMC STORAGE EQ $7 \quad 0.180 E-02 \quad 0.01$ PBB1-FR1-PRL1 R22S01

LLW INEL RWMC STORAGE EQ 8 0.178E-04 0.01 PBB1-FR1-EXP1 R22SB0

LLW INEL RWMC STORAGE EQ $90.180 \mathrm{E}-06 \quad 0.02$ PBB1-FR1-EXP1-DET1 R22SD0

LLW INEL RWMC STORAGE EQ $10 \quad 0.178 \mathrm{E}-02 \quad 0.1$ PBB1-FR1-SFR1 R22L00

LLW INEL RWMC STORAGE EQ 11 0.198E-03 0.1 PBB1-FR1-SFR1-PRL1 R22L01

LLW INEL RWMC STORAGE EQ 12 0.180E-04 0.1 PBB1-FR1-SFR1-EXP1 R22LB0

LLW INEL RWMC STORAGE EQ $130.200 \mathrm{E}-050.1$ PBB1-FR1-SFR1-EXP1-DET1 R22LD0

FIGURE C.3 Sample WASTE_ETA Output File: File Ready for Database Loading in WASTE_ACC 


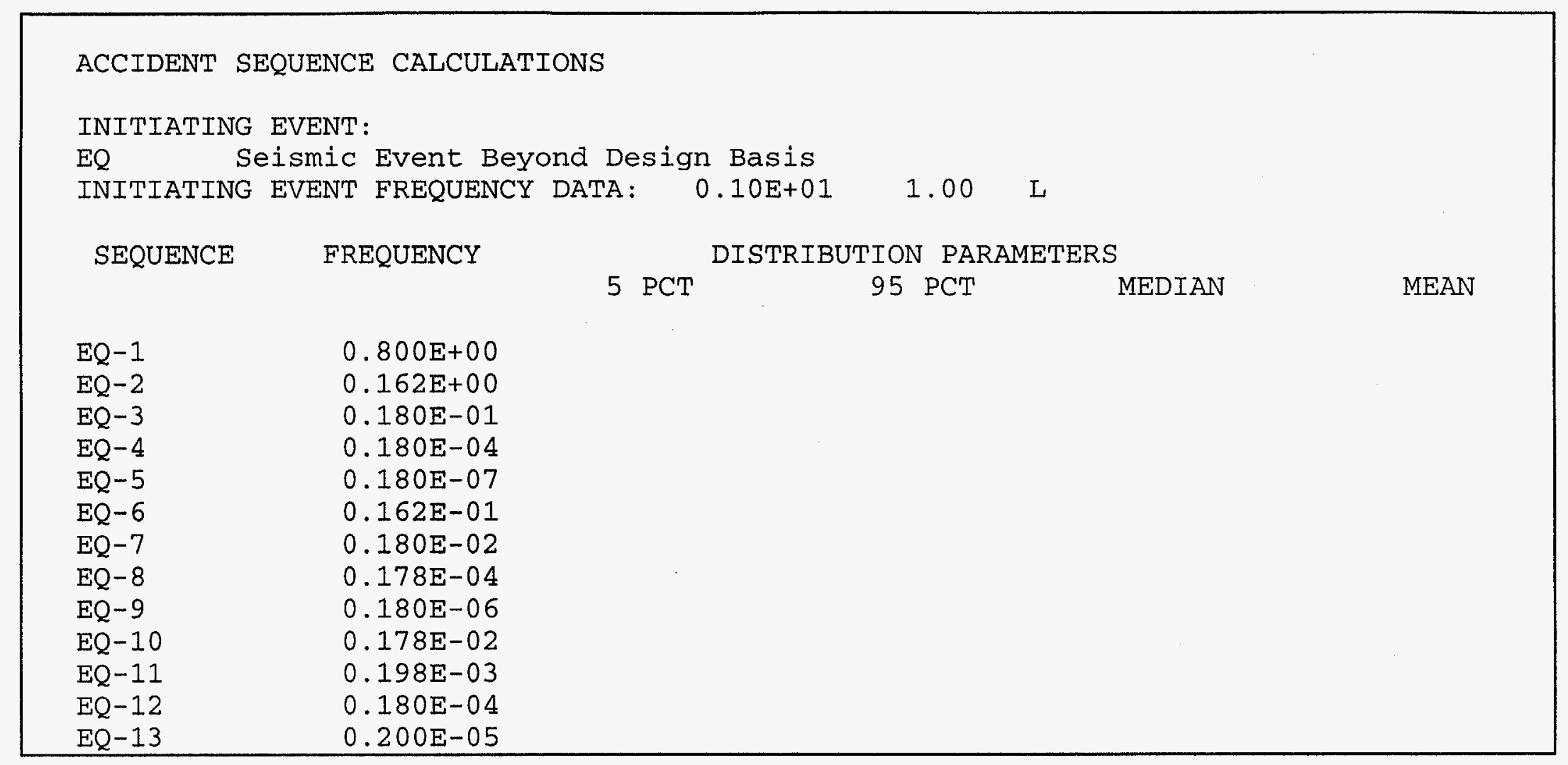

FIGURE C.4 Sample WASTE_ETA Output File: Summary of Results 


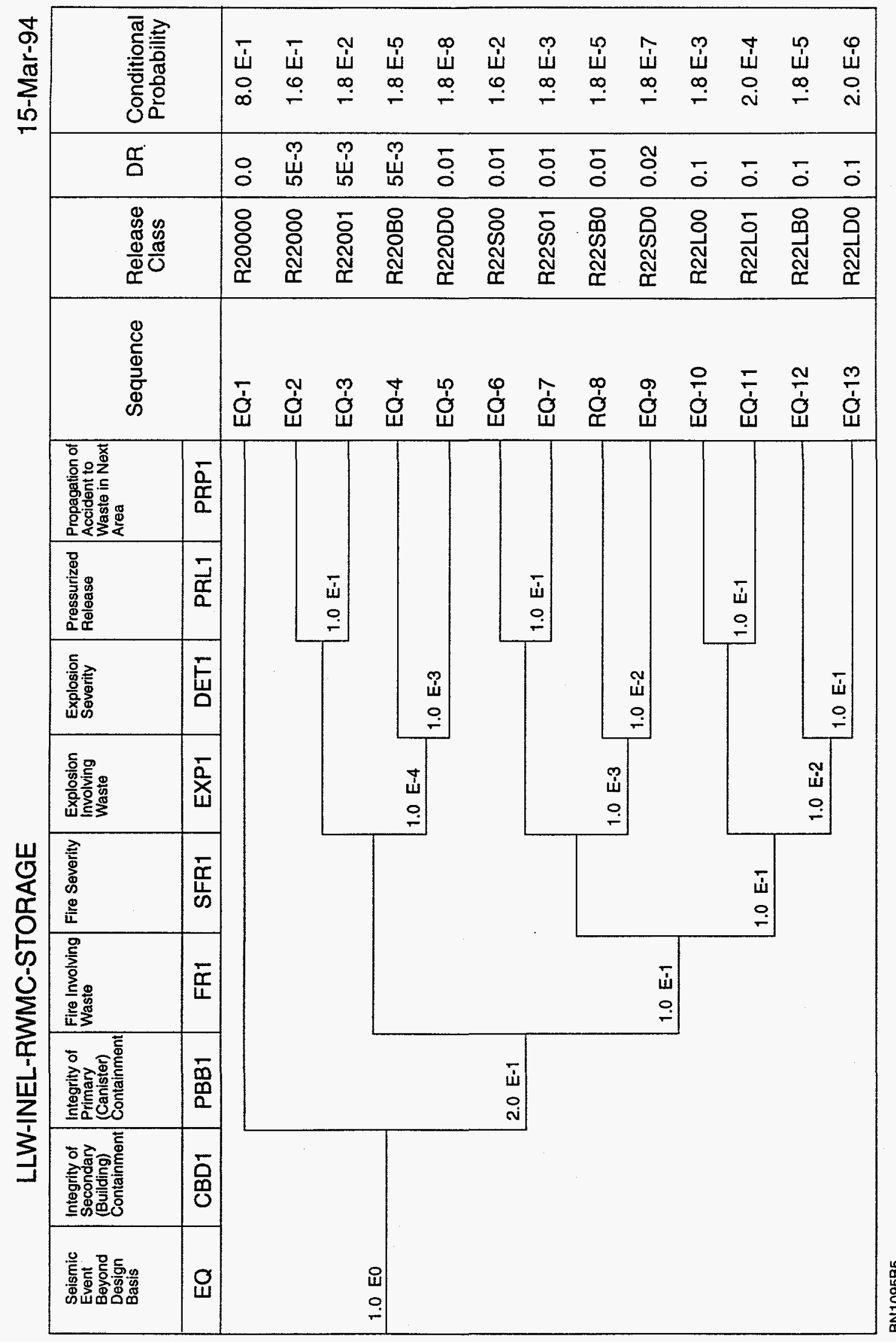

完 